Check for updates

Cite this: RSC Adv., 2018, 8, 24128

Received 23rd May 2018

Accepted 20th June 2018

DOI: $10.1039 / c 8 r a 04385 j$

rsc.li/rsc-advances

\title{
Electroactive Co(III) salen metal complexes and the electrophoretic deposition of their porous organic polymers onto glassy carbon $\uparrow$
}

\author{
Marcello B. Solomon, (D) ${ }^{a}$ Aditya Rawal, ${ }^{b}$ James M. Hook, (D) ${ }^{b}$ Seth M. Cohen, (D) ${ }^{c}$ \\ Clifford P. Kubiak, (D) Katrina A. Jolliffe (D) *a and Deanna M. D'Alessandro (iD)*a
}

\begin{abstract}
This paper reports the $\mathrm{CO}_{2}$ electroreduction properties of three bis-bromo Co(III) salen metal complexes and their Porous Organic Polymers (POPs) as a platform for using the salen core as a multi-electron reducing agent. Although Co(III) salen metal complexes have been studied extensively for their chemical catalysis with $\mathrm{CO}_{2}$, their electrochemical behaviour, particularly their reduction, in the presence of $\mathrm{CO}_{2}$ is much less explored. The discrete Co(III) complexes enabled the reduction of $\mathrm{CO}_{2}$ to $\mathrm{CO}$ in faradaic efficiencies of up to $20 \%$. The reductive electrochemical processes of Co(III) salen complexes are relatively unknown; therefore, the mechanism of reduction for the complexes was investigated using IR and UV-Vis-NIR spectroelectrochemical (SEC) techniques. The discrete bis-bromo salen complexes were incorporated into POPs with tris-( $p$-ethynyl)-triphenylamine as a co-ligand and were characterised using solid state NMR, IR, UV-Vis-NIR and Field Emission Scanning Electron Microscopy (FE-SEM). The POP materials were electrophoretically deposited onto glassy carbon under milder conditions than those previously reported in the literature. Direct attachment of the POP materials to glassy carbon enabled improved solid state electrochemical analysis of the samples. The POP materials were also analysed via SEC techniques, where a Co(॥/I) process could be observed, but further reductions associated with the imine reduction compromised the stability of the POPs.
\end{abstract}

\section{Introduction}

Since the industrial revolution, the consumption of fossil fuels has been rapidly increasing to cater for the needs of an ever growing world population. Industrialisation has been heavily dependent on the use of coal, which today is responsible for over $40 \%$ of the production of electricity worldwide. ${ }^{1}$ In excess of 12 million tonnes of oil and 8 million cubic tonnes of natural gas are consumed daily to provide energy, which has resulted in excess carbon dioxide $\left(\mathrm{CO}_{2}\right)$ emissions into the atmosphere at a rate faster than the current carbon cycle can mitigate. ${ }^{2-10}$ Carbon capture and sequestration (CCS) has long been seen as a viable option as it allows for the retrofitting of existing power plants to separate $\mathrm{CO}_{2}$ from the flue stream prior to its release into the atmosphere. ${ }^{11} \mathrm{~A}$ concern arising from the storage of $\mathrm{CO}_{2}$ is its effective transport, which poses

${ }^{a}$ School of Chemistry, The University of Sydney, New South Wales 2006, Australia. E-mail: deanna.dalessandro@sydney.edu.au; kate.jolliffe@sydney.edu.au; Fax: +61 29351 3329; Tel: +61293513777

${ }^{b}$ NMR Facility, Mark Wainwright Analytical Centre, The University of New South Wales, 2052, Australia

'Department of Chemistry and Biochemistry, University of California, San Diego, California 92093, USA

$\dagger$ Electronic supplementary information (ESI) available. See DOI: $10.1039 / \mathrm{c} 8 \mathrm{ra} 04385 \mathrm{j}$ financial, logistical and environmental challenges. Other chief concerns for CCS are the safety and environmental aspects that arise from the high pressures and large concentrations of $\mathrm{CO}_{2}$. Processes that can combine the capture of $\mathrm{CO}_{2}$ with its use as a feedstock may assist in the handling of emissions.

The benefit of using $\mathrm{CO}_{2}$ as a feedstock lies in its abundance and low cost; however, its use as a cheap feedstock is limited by the presence of $\mathrm{C}$ in its most oxidised form. Investing energy to convert $\mathrm{CO}_{2}$ into a more reactive intermediate could enable the generation of commodity chemicals, which could eventually provide a cleaner fuel source for the human population to use. From a thermodynamic viewpoint, $\mathrm{CO}_{2}$ can accept an electron to form a $\mathrm{CO}_{2}{ }^{--}$radical anion, but this is only observed directly at high reduction potentials $\left(E_{\mathrm{pc}}=-1.90 \mathrm{~V} v s\right.$. NHE). ${ }^{12,13}$ The proton-coupled reduction of $\mathrm{CO}_{2}$ provides a feasible alternative to direct reduction and can lead to the generation of useful products (carbon monoxide or formic acid) at lower reduction potentials. ${ }^{\mathbf{1 3} 14}$ It is important that there is a kinetic preference for $\mathrm{CO}_{2}$ reduction over $\mathrm{H}_{2}$ due to the required presence of a proton source to facilitate the process.

Porous Organic Polymers (POPs) are considered viable candidates as materials that can both capture and convert $\mathrm{CO}_{2}$ into commodity chemicals. They are generally cheap to produce, simple to synthesise on a larger scale, possess high thermal and chemical stability, ${ }^{15}$ are lightweight, contain 
hydrophobic pores from their extended aromaticity and are chemically resistant. Hupp and co-workers have previously shown that the porosity and stability of POPs can be exploited by generating a polymer based on cheap and abundant amineand anhydride-bearing monomers. ${ }^{16}$ The activated polymer demonstrated stability up to $500{ }^{\circ} \mathrm{C}$ and retained porosity after exposure to $\mathrm{HCl}$. Patel and co-workers explored $\mathrm{N}_{2}$-phobicity within POPs by generating a class of nitrogen-rich azo POPs, which possessed high point selectivity for $\mathrm{CO}_{2} / \mathrm{N}_{2}(S=288$ at $323 \mathrm{~K}$ ) and were chemically stable in boiling water. ${ }^{17}$ Zhou and co-workers synthesised POPs containing tetratopic adamantane cages which exhibited BET surface areas up to 5400 $\mathrm{m}^{2} \mathrm{~g}^{-1}$ and were suitable for $\mathrm{CO}_{2}$ and $\mathrm{CH}_{4}$ separation. ${ }^{18}$ It was found through ideal adsorbed solution theory (IAST) that several high surface area POPs demonstrated selectivity for $\mathrm{CO}_{2}$ at $295 \mathrm{~K}$, suggesting their suitability for $\mathrm{CO}_{2}$ capture. Many early studies of POPs exploited porosity as their most important property; however, subsequent studies identify that these materials can also have applications in catalysis. ${ }^{19}$ Bare metal sites can also be incorporated into POPs, which may promote their use in catalysis. ${ }^{\mathbf{2 0 , 2 1}}$

Creating a class of solid state materials that is capable of both the capture of $\mathrm{CO}_{2}$ and its catalytic conversion requires the choice of multifunctional building blocks. The ubiquity of salen metal complexes over the past eighty years has shown that they are capable of diverse chemistry. Since the first reported preparation of the vibrantly coloured salen-based ligands in 1933 by Pfeiffer, ${ }^{22}$ this class of ligand has found extensive use in chemical catalysts, ${ }^{23}$ electrochemical agents, ${ }^{24}$ and charge transfer complexes, ${ }^{25}$ among other applications. The variability of substituents on the salen core enables the preparation of diverse libraries of compounds that may be generated by systematic variation. ${ }^{26}$ There is scope to modify substituents along the backbone of the salen ligand to study their steric and electronic influence on catalysis (Fig. 1). The inherently redox-active nature of the salen metal complex allows for its properties to be modulated.

The readily functionalisable core of the salen metal complex allows for its covalent immobilisation into a POP material. A class of salen-based POPs were reported by Chun and co-workers, who varied the bridging moiety in the salen to incorporate the diaminocyclohexane functionality, and introduced $\mathrm{Al}(\mathrm{III}), \mathrm{Co}(\mathrm{III})$ and $\mathrm{Cr}(\mathrm{III})$ metals into the chelating site.

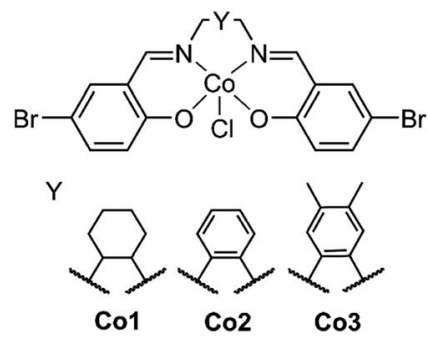

Fig. 1 The structure of the salen metal complexes used here. The backbone can be systematically modified by varying $Y$ to produce the analogs Co1, Co2 and Co3.
Not only did these polymers exhibit similar BET surface areas of 522-650 $\mathrm{m}^{2} \mathrm{~g}^{-1}$, but they also converted $\mathrm{CO}_{2}$ to cyclic carbonates with yields of up to $94 \% .{ }^{20}$ Xie and co-workers also used POPs to examine the capture of $\mathrm{CO}_{2}$ and its conversion to propylene carbonate under mild conditions. ${ }^{27}$ Surface areas up to $965 \mathrm{~m}^{2} \mathrm{~g}^{-1}$ were achieved and the catalyst could be recycled up to 22 times without any significant decrease in activity. To the best of our knowledge, work has not yet appeared on the electrochemical reduction of salen-based POPs.

The electrochemical examination of POP materials requires their effective attachment to a conductive surface. ${ }^{28}$ A large proportion of the literature addressing the surface attachment of solid state materials (in particular Metal Organic Frameworks (MOFs)) onto a conductive surface has reported Indiumdoped Tin Oxide (ITO) or Fluorine-doped Tin Oxide (FTO) on glass as the substrate of choice. ${ }^{29-33}$ These two substrates are both transparent, and therefore allow for the spectroscopic study of the surface attached material prior to, during and after reduction experiments using transmission measurements; ${ }^{34}$ however, there are limitations to their use. For example, ITO readily corrodes from glass substrates upon the application of highly anodic and cathodic potentials, and indium is a scarce and expensive element. ${ }^{35}$ Although FTO coated glass has a larger electrochemical window and uses more abundant fluorine, it has a high resistance, which affects the reversibility of the ferrocene/ferrocenium ion $\left(\mathrm{Fc}^{0} / \mathrm{Fc}^{+}\right)$ couple. ${ }^{36}$ Glassy carbon is more conductive than FTO and ITO coated glass, and is therefore is a strong candidate as the substrate for solid state electrochemistry. The major limitation for glassy carbon is that mechanical immobilisation of materials such as POPs is difficult. Electrophoretic deposition (EPD) has been successfully applied to synthesise homogeneous, continuous films of UiO, MIL, NU, ${ }^{30}$ ZIF $^{37}$ and porphyrin-based $^{38}$ MOFs. The limitations of this particular surface attachment method lie in the high voltages required for deposition to occur. It is likely that immobilising of a POP onto glassy carbon using EPD could be achieved at lower voltages. $^{39}$

Herein, we report the synthesis of three Co(III) salen metal complexes to explore their use as electrochemical reducing agents for $\mathrm{CO}_{2}$. The electrochemical properties of the discrete complexes are analysed to examine the effect of modulating the bridging diamine functionality of the complexes on their electrochemical properties. We perform a detailed electrochemical study on the conversion of $\mathrm{CO}_{2}$ using these complexes to address the gap in the literature regarding salen complexes as reducing agents. We also report the inclusion of the discrete complexes into novel POPs and examine the impact of salen immobilisation on their redox properties. We further report a method for the surface attachment of POPs onto glassy carbon via EPD which uses milder potentials than those previously reported for EPD onto an FTO substrate, thus providing a benign pathway for attaching solid-state materials to glassy carbon. 


\section{Experimental Methods}

General

All chemicals used were purchased from Aldrich, Alfa Aesar and Merck, and were used without further purification unless stated otherwise. Solvents were obtained from a PureSolv system, or purchased and used without further purification. Low resolution electrospray ionisation mass spectra (ESI-MS) were acquired as a solution in $\mathrm{MeCN}, \mathrm{MeOH}$ or DMF with a $100 \mu \mathrm{L} \min ^{-1}$ flow rate on a Finnegan LCQ or amazon MS detector. Spectra were collected over the mass range $\mathrm{m} / \mathrm{z} 100$ to 1000. An ESI spray voltage of $5 \mathrm{kV}$ was applied with a heated capillary temperature of $200{ }^{\circ} \mathrm{C}$ and a nitrogen sheath gas pressure of 60 psi. Melting points were measured using a Gallenkamp melting point apparatus with the sample placed in a glass capillary. The final melting points are uncorrected. Room temperature FT-IR spectra were obtained using a PerkinElmer UATR 2 infrared spectrometer over the range $400-4000 \mathrm{~cm}^{-1}$ with a resolution of $4 \mathrm{~cm}^{-1}$. Samples were mechanically compressed on the surface of a diamond crystal on which the background was collected. ICP-OES was performed at the Mark Wainwright Analytical Centre at The University of New South Wales.

\section{Nuclear magnetic resonance}

Solution state ${ }^{1} \mathrm{H}$ and ${ }^{13} \mathrm{C}\left\{{ }^{1} \mathrm{H}\right\}$ NMR spectra were recorded on a Bruker AVANCEIII 300, 400 or 500 spectrometer operating at 300, 400, $500 \mathrm{MHz}$ for ${ }^{1} \mathrm{H}$ and $75,100,125 \mathrm{MHz}$ for ${ }^{13} \mathrm{C}$, respectively. ${ }^{1} \mathrm{H}$ and ${ }^{13} \mathrm{C}$ NMR chemical shifts were referenced internally to residual solvent resonances. Spectra were recorded at $298 \mathrm{~K}$ and chemical shifts $(\delta)$, with uncertainties of $\pm 0.01 \mathrm{~Hz}$ for ${ }^{1} \mathrm{H}$ and $\pm 0.05 \mathrm{~Hz}$ for ${ }^{13} \mathrm{C}$, are quoted in ppm. Coupling constants $(J)$ are quoted in $\mathrm{Hz}$ and have uncertainties of $\pm 0.05 \mathrm{~Hz}$ for ${ }^{1} \mathrm{H}-{ }^{1} \mathrm{H}$. Deuterated solvents were obtained from Cambridge Stable Isotopes and used as received. Chemical shifts for all ligands are reported relative to the deuterated solvents used. ${ }^{40}$

The ${ }^{13} \mathrm{C}$ cross polarisation magic angle spinning (CPMAS) solid state NMR experiments on the diamagnetic discrete complexes and their polymers were carried out at The Mark Wainwright Analytical Centre, The University of New South Wales, on a wide-bore Bruker Biospin AVANCEIII solids-300 $\mathrm{MHz}$ spectrometer operating at a frequency of $75 \mathrm{MHz}$ for the ${ }^{13} \mathrm{C}$ nucleus. The sample $(\sim 80 \mathrm{mg})$ was placed into $4 \mathrm{~mm}$ zirconia rotors fitted with Kel-f® caps and spun in a double resonance $\mathrm{H}-\mathrm{X}$ probehead at $8 \mathrm{kHz}$ magic angle spinning (MAS). The ${ }^{13} \mathrm{C}$ and ${ }^{1} \mathrm{H} 90^{\circ}$ radio frequency pulse lengths were optimised to $3.5 \mu$ s each. The ${ }^{13} \mathrm{C}$ spectra were acquired with $1 \mathrm{~ms}$ cross polarisation contact time with a total suppression of spinning side bands (TOSS) scheme, followed by ${ }^{1} \mathrm{H}$ decoupling at $75 \mathrm{kHz}$ field strength using spinal-64 decoupling. The ${ }^{13} \mathrm{C}$ non-quaternary suppression (NQS) spectra were recorded by turning off the ${ }^{1} \mathrm{H}$ decoupling for $40 \mu$ s during the TOSS period. For sufficient signal-to-noise, $c a$. $10 \mathrm{~K}$ transients were acquired for each sample with recycle delays of $3.0 \mathrm{~s}$ in between to ensure sufficient relaxation of the ${ }^{1} \mathrm{H}$ nuclei. The spectra were obtained at room temperature. The ${ }^{13} \mathrm{C}$ chemical shifts were referenced to the glycine $\mathrm{CO}$ peak at $176 \mathrm{ppm}$.

\section{Cyclic voltammetry}

Solution and solid state electrochemical measurements were performed using a Bioanalytical Systems BASi Epsilon Electrochemical Analyser at 298 K. A single compartment cell was used, consisting of either a glassy carbon working electrode $(3.0 \mathrm{~mm}$ diameter) for solution state or a glassy carbon plate (active area of $2 \mathrm{~cm}^{2}$ ) with immobilised polymer attached through a steel alligator clip to tinned copper wire for solid state, a platinum wire auxiliary electrode and an electrolysed $\mathrm{Ag} / \mathrm{AgCl}$ wire reference electrode separated from the solution by a CoralPor tip. Cyclic and differential pulse voltammograms were performed using a $10 \mathrm{~mL}$ solution of the analyte $(1 \mathrm{mM}$ complex in $0.1 \mathrm{M}$ $\left[\left(n-\mathrm{C}_{4} \mathrm{H}_{9}\right)_{4} \mathrm{~N}\right] \mathrm{PF}_{6}$ in either MeCN or DMF). The solution was purged with dried $\mathrm{N}_{2}$, Ar, or $\mathrm{CO}_{2}$ prior to each experiment. Ferrocene (Fc) (1 mM) was added as an internal standard during each experiment. All potentials are quoted in $\mathrm{V} v s . \mathrm{Fc}^{0} / \mathrm{Fc}^{+}$. Uncompensated resistance between the working and the reference electrodes was corrected by using $i_{\mathrm{R}}$ compensation on the potentiostat. Scan rate dependence studies were carried out for each complex between $50-1600 \mathrm{mVs}^{-1}$ to ensure the homogeneity of the system.

\section{Infrared spectroelectrochemistry (IR SEC)}

Solution state IR SEC was performed on the discrete complexes using the IR-SEC cell previously reported by Kubiak et al. ${ }^{41} \mathrm{~A}$ Pine Instrument Co. Model AFCBP1 potentiostat was employed to control the cell potential, referenced to $\mathrm{Ag} / \mathrm{Ag}^{+}$. Thin-layer bulk electrolysis was measured by reflectance IR off the electrode as the potential was scanned. All experiments were conducted in $0.1 \mathrm{M}\left[\left(n-\mathrm{C}_{4} \mathrm{H}_{9}\right)_{4} \mathrm{~N}\right] \mathrm{PF}_{6} / \mathrm{MeCN} / \mathrm{DMF}(9: 1)$ with known analyte loadings prepared under an inert atmosphere. FT-IR spectra were recorded on a Thermo Scientific Nicolet 6700, with resolution of $4 \mathrm{~cm}^{-1}$. Unlike the CV or UV-Vis-NIR SEC experiments, it was not possible to use pure DMF in the IR SEC experiments, since the strong $\nu_{\mathrm{C}=\mathrm{O}}$ stretching vibration at $1740 \mathrm{~cm}^{-1}$ overwhelmed the comparatively weaker $\nu_{\mathrm{C}=\mathrm{N}}$ stretch expected from the salen metal complex at $\sim 1600 \mathrm{~cm}^{-1}$.

\section{Ultraviolet-visible-near infrared spectroelectrochemistry (UV- Vis-NIR SEC)}

Solution state UV-Vis-NIR SEC was measured over the range 5000-35000 $\mathrm{cm}^{-1}$ using a CARY5000 spectrophotometer interfaced to Varian WinUV software. The absorption spectra of the electrogenerated species were obtained in situ by the use of an Optically Semi-Transparent Thin-Layer Electrosynthetic cell, path length $0.685 \mathrm{~mm}$, mounted in the path of the spectrophotometer. Solutions for the spectroelectrochemical experiment contained $0.1 \mathrm{M}\left[\left(n-\mathrm{C}_{4} \mathrm{H}_{9}\right)_{4} \mathrm{~N}\right] \mathrm{PF}_{6} / \mathrm{MeCN}$ or $[(n$ $\left.\left.\mathrm{C}_{4} \mathrm{H}_{9}\right)_{4} \mathrm{~N}\right] \mathrm{PF}_{6} / \mathrm{DMF}$ supporting electrolyte and $c a .0 .4 \mathrm{mM}$ of the compound for analysis. Appropriate potentials were applied by using an eDAQ e-corder 410 potentiostat and the current was carefully monitored throughout the electrolysis. The electrogenerated species formed in situ, and their absorption spectra 
were recorded at regular intervals through the electrolysis. The attainment of a steady-state spectrum and the decay of the current to a constant minimum at a potential appropriately beyond $E_{1 / 2}$ (for the redox process) was indicative of the complete conversion of the starting material.

Solid state diffuse reflectance UV-Vis-NIR spectra of the redox-active species were collected in situ using a CARY5000 UV-Vis-NIR spectrophotometer equipped with a Harrick Omni Diff Probe attachment interfaced to Varian WinUV software over the range $5000-25000 \mathrm{~cm}^{-1}$ in a custom-made cell previously reported by D'Alessandro et $a .^{42}$ The cell consisted of a Pt wire counter electrode and a $\mathrm{Ag} / \mathrm{Ag}^{+}$quasi-reference electrode. The solid sample was immobilised by a thin strip of Teflon tape onto a $0.1 \mathrm{~mm}$ thick Indium-doped Tin Oxide (ITO) coated quartz slide, which functioned as the working electrode. The applied potential was controlled using an eDAQ potentiostat. Continuous scans of the sample were obtained and the potential increased gradually until a change in the spectrum was observed.

\section{Bulk electrolysis}

Solution and solid state bulk electrolysis were performed in a threaded $60 \mathrm{~mL}$ single compartment cell with a custom airtight Teflon top, as reported by Kubiak et al. ${ }^{43}$ The set-up consisted of a carbon rod (surface area $=7.4 \mathrm{~cm}^{2}$ ) for solution state or glassy carbon plate with immobilised POP for solid state as the working electrode (active area $=2 \mathrm{~cm}^{2}$ ), a coiled Pt wire counter electrode protected from the bulk solution by fritted glass and an electrolysed $\mathrm{Ag} / \mathrm{AgCl}$ pseudo reference, separated from solution by a CoralPor tip. The analyte solution $(\sim 40 \mathrm{~mL})$ consisted of complex $(1-2 \mathrm{mM})$ in $0.1 \mathrm{M}\left[\left(n-\mathrm{C}_{4} \mathrm{H}_{9}\right)_{4} \mathrm{~N}\right] \mathrm{PF}_{6} / \mathrm{MeCN} /$ $\operatorname{DMF}(8: 2)$. The solution was purged with $\mathrm{CO}_{2}$ for 20 min prior to each electrolysis experiment, with the optimal applied potential determined by the CV experiments.

Gas phase analysis was performed by sampling $1 \mathrm{~mL}$ of the headspace of the cell at $20 \mathrm{~min}$ intervals and injecting into a Hewlett-Packard 7890A series gas chromatograph with two molecular sieve columns $(30 \mathrm{~m} \times 0.53 \mathrm{~mm}$ i.d. $\times 25 \mu \mathrm{m}$ film $)$. The $1 \mathrm{~mL}$ injection was split between two columns, one with $\mathrm{N}_{2}$ carrier gas and one with $\mathrm{He}$ carrier gas to quantify both $\mathrm{CO}$ and $\mathrm{H}_{2}$ respectively. Instrument specific calibration curves were measured prior to analysis to determine the amount of each gas produced.

Solution phase analysis was performed on the bulk solution to quantify formic acid production by sampling the bulk electrolysis solution $(5 \mathrm{~mL})$ after electrolysis. $\mathrm{D}_{2} \mathrm{O}(1 \mathrm{~mL})$ was added to the solution and this was well mixed, prior to its dilution with dichloromethane. The $\mathrm{D}_{2} \mathrm{O}$ layer was separated prior to the addition of concentrated hydrochloric acid (1 drop). Samples were analysed by ${ }^{1} \mathrm{H}$ NMR and spectra were recorded on a Bruker AVANCEIII 300 spectrometer operating at $300 \mathrm{MHz}$ for ${ }^{1} \mathrm{H}$. Spectra were recorded at $298 \mathrm{~K}$.

\section{Thermogravimetric analysis}

TGA measurements were carried out on a TA Instruments HiRes 2950 Thermogravimetric Analyser or Discovery
Thermogravimetric Analyser. Dry $\mathrm{N}_{2}\left(0.1 \mathrm{~L} \mathrm{~min}^{-1}\right)$ flowed over the sample during data collection. The sample temperature was ramped at $1{ }^{\circ} \mathrm{C} \mathrm{min}{ }^{-1}$ from 25 to $600{ }^{\circ} \mathrm{C}$. Samples were loaded dry after exposure to air.

\section{Gas adsorption}

Adsorption isotherms were measured using the Accelerated Surface Area \& Porosity (ASAP) 2020 or the 3-Flex, both supplied by Micromeritics Instruments Inc. The sample ( 50-100 mg) was loaded into a glass analysis tube and outgassed for $24 \mathrm{~h}$ under vacuum at $80^{\circ} \mathrm{C}$, prior to analysis.

$\mathrm{N}_{2}$ adsorption and desorption isotherms were measured at $77 \mathrm{~K}$ and data were analysed using the Brunauer, Emmett and Teller (BET) models to determine the surface area. ${ }^{44}$ Pore size distributions were calculated using the Density Functional Theory (DFT) cylindrical model in the Micromeritics MicroActive Software Package Version 4.03.

\section{Electrophoretic deposition (EPD) onto glassy carbon}

Glassy carbon substrates were cut to $3 \times 1 \mathrm{~cm}$ electrodes. The POP $(20 \mathrm{mg})$ was suspended in toluene $(20 \mathrm{~mL})$ and sonicated for $30 \mathrm{~s}$. Two identical glassy carbon substrates were dipped into the deposition solution (1 $\mathrm{cm}$ separation distance) and a constant DC voltage of $30 \mathrm{~V}$ was applied from an Extech 382270 High Precision Quad Output DC power supply. The deposition occurred over a period of $6 \mathrm{~h}$, with a stirred suspension that was sonicated every 30 minutes to break up larger aggregates of POP. Caution: electrical sparking due to the accidental contact of electrodes and/or their leads can result in the spontaneous ignition of toluene. Prior to the undertaking of these experiments, ensure that the experiment is set up in an empty fume hood, clear of flammables and with a blast shield.

\section{Field emission scanning electron microscopy}

FE-SEM measurements were obtained at either the Nano3 facility at The University of California, San Diego or at the Australian Centre for Microscopy \& Microanalysis at The University of Sydney. POP materials were deposited onto a glassy carbon substrate, which was adhered to conductive carbon tape on a sample holder disk. The disk was coated using a Cr-sputter coating for $8 \mathrm{~s}$. A Philips XL30 ESEM was used for acquiring images using a $10 \mathrm{kV}$ energy source under vacuum at a working distance at $10 \mathrm{~mm} . \sim 19000 \times$ magnification images were collected.

\section{Results and discussion}

\section{Synthesis and structural characterisation}

The synthesis of salen ligands was achieved by the Schiff-base condensation of 5-bromosalicylaldehyde with varying bridging diamines to afford the free-base salen in good yield. $\mathrm{Co}(\mathrm{III})$ metalation was achieved by the addition of $\mathrm{Co}(\mathrm{OAc})_{2} \cdot 4 \mathrm{H}_{2} \mathrm{O}$ in the presence of $\mathrm{LiCl}$ as an oxidising agent to afford all $\mathrm{Co}(\mathrm{III})$ complexes in good yields (Scheme 1A). Salen metal complexes were successfully incorporated into POPs via a SonogashiraHagihara palladium cross coupling reaction between $\operatorname{tris}(p-$ 
ethynyl)triphenylamine (TPA) and the bis-bromo salen metal complexes under an inert $\mathrm{N}_{2}$ atmosphere in the presence of $\left[\mathrm{Pd}\left(\mathrm{PPh}_{3}\right)_{4}\right]$ and $\mathrm{CuI}$ to form the series of POPs. In all reaction mixtures, the light yellow solution darkened and a brown precipitate formed (Scheme 1B).

Extensive characterisation was performed on the amorphous polymers to determine their composition. Despite their noncrystalline nature, TGA studies revealed that all POPs possessed thermal stability above $200{ }^{\circ} \mathrm{C}$, with a number of polymers showing thermal stability of up to $400{ }^{\circ} \mathrm{C}$, prior to partial thermal degradation (Fig. S1 $\dagger$ ). IR experiments indicated that the TPA co-ligand was covalently linked to the salen metal complex. The IR spectrum of TPA exhibited a $\nu_{\mathrm{C}} \equiv \mathrm{H}$ stretch at $3264 \mathrm{~cm}^{-1}$, which disappeared upon polymerisation. The weak $\nu_{\mathrm{C} \equiv \mathrm{C}}$ stretch also shifted from $2102 \mathrm{~cm}^{-1}$ in the monomer to $2191 \mathrm{~cm}^{-1}$ in the polymer. ${ }^{45}$ The $\nu_{\mathrm{C}=\mathrm{N}}$ stretch belonging to the imine in the salen metal complex was observed to shift upon incorporation into the salen POP compared with the polymer (Fig. S2†). Further evidence of the covalent linkage between coligand and salen was detected in the UV-Vis-NIR spectra of the monomers and polymers. The UV-Vis-NIR spectrum of TPA exhibited a sharp $n-\pi^{*}$ charge transfer at $26460 \mathrm{~cm}^{-1}$ and $\pi-$ $\pi^{*}$ charge transfer bands at 31970 and $34260 \mathrm{~cm}^{-1}$. When compared to the discrete salen complexes, many of the characteristic charge transfer bands in the salen metal complexes were shifted to lower energies in the polymers, consistent with polymeric systems that are more delocalised. The UV-Vis-NIR spectra of the polymers all exhibited the $n-\pi^{*}$ charge transfer band, consistent with TPA incorporation into the polymer (Fig. S3 $\uparrow$ ). ICP-OES indicated that the Co(III) salen was incorporated into the POP; however, the lower than calculated values for the $\mathrm{Co}$ (III) content suggests that homocoupling between the TPA may be occurring because of uncontrolled propagation, as well as the possible leaching of the Co(III) species (Table S1†).

Solid state ${ }^{13} \mathrm{C}$ NMR experiments were performed to further characterise the salen-based POPs. Solid state ${ }^{13} \mathrm{C}$ NMR spectra could be obtained for POPCo1, POPCo2 and POPCo3, which all contain the $\mathrm{Co}(\mathrm{III}) \mathrm{d}^{6}$ species. This implies that the Co(III) salen metal complexes are low spin when incorporated into the POPs. The ${ }^{13} \mathrm{C}$ CPMAS spectra of the polymers containing the diamagnetic salen metal complexes were collected and compared to the discrete complexes to show incorporation of the salen into the POP (Fig. 2, S4-S6†). A shift in the position of the alkynyl peaks from those observed in discrete TPA previously reported, ${ }^{46}$ as well as their broadening, suggests that a polymeric material has formed. Evidence for the incorporation of the salen metal complex came from the appearance of peaks from the bridging diamine around 160165 ppm, corresponding to the imine carbon and phenolic carbon environments present in the salen. These varied dependent on the bridging moiety. The comparatively small signal intensity of the salen moiety suggests an incorporation

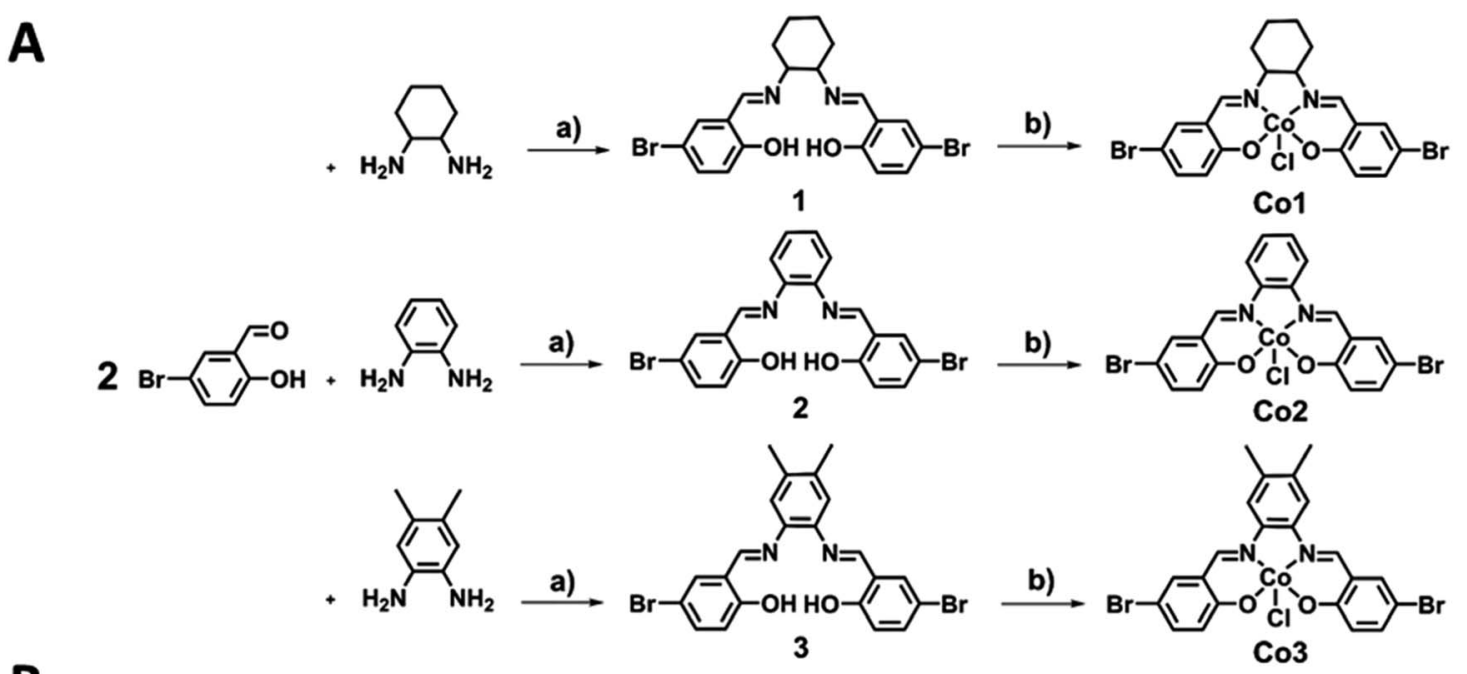

B

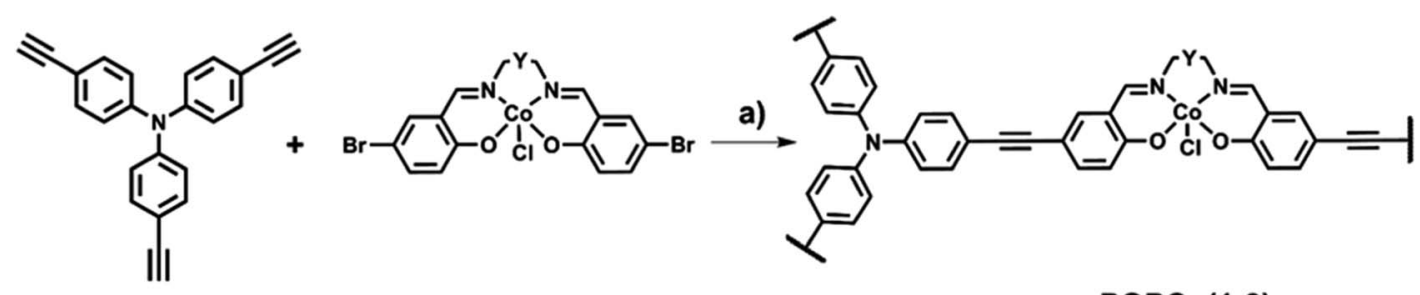

POPCo(1-3)

Scheme 1 (A) Synthesis of bromo-terminated $\mathrm{Co}(\mathrm{III})$ salen metal complexes (a) solvent: $\mathrm{MeOH}, 80{ }^{\circ} \mathrm{C}, 2 \mathrm{~h},(\mathrm{~b}) \mathrm{metal}: \mathrm{Co}(\mathrm{OAc})_{2} \cdot 4 \mathrm{H}_{2} \mathrm{O}(1.1 \mathrm{eq}$.), $\mathrm{LiCl}\left(4\right.$ eq.), solvent: EtOH, r.t., 48 h. (B) Synthesis of the Co(II) salen polymer (a) catalysts: $\left[\mathrm{Pd}\left(\mathrm{PPh}_{3}\right)_{4}\right](30 \mathrm{~mol} \%)$, Cul (30 mol\%), solvent: toluene/ $\mathrm{EtOH}(2: 1), 85^{\circ} \mathrm{C}, 72 \mathrm{~h}$. 

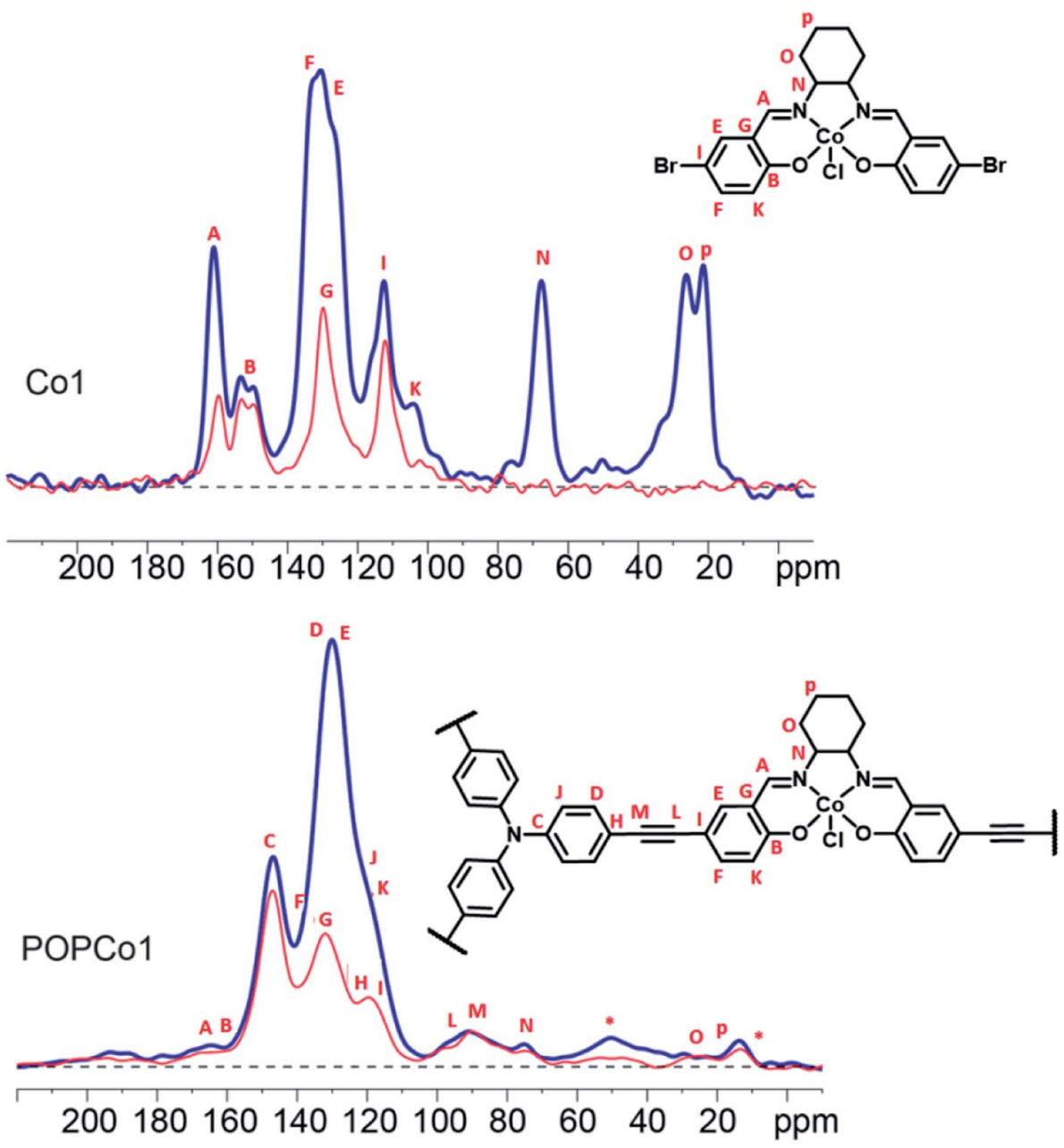

Fig. $2{ }^{13} \mathrm{C}$ CPTOSS of $\mathrm{Co}$ (above) and POPCo1 (below). The full ${ }^{13} \mathrm{C}$ NMR spectrum is plotted in blue, while the spectrum in red is the nonprotonated methyl/carbon species detected after $40 \mu \mathrm{s}$ of dipolar dephasing. The signals marked * are attributed to excess triethylamine, which was unable to be completely removed from the pores.

of salen around $10 \%$, which is consistent with the ICP-OES data (Table S1 $\dagger$ ). Variation in the incorporated salen metal complex could be deduced from the appearance of different carbon environments at lower field. For POPCo1, evidence for the diaminocyclohexane bridging moiety came from the appearance of peaks corresponding to the $\mathrm{sp}^{3}$ hybridised secondary and quaternary carbons on the bridging diamine between $20-30$, and $70 \mathrm{ppm}$. The additional signals in the alkyl region at 15 and $50 \mathrm{ppm}$ have been tentatively assigned to small quantities of residual triethylamine. For the aromatic POPCo2 and POPCo3, a larger integration under the aromatic signals from 110-160 ppm was detected, which implies additional carbon environments from the discrete complexes Co2 and Co3, respectively (Fig. S4 and S5 $\dagger$ ). Finally, the synthesis was repeated in the absence of salen metal complex, forming POPTPA. The ${ }^{13} \mathrm{C}$ CPMAS spectrum for this deliberately homocoupled polymer POPTPA demonstrated the absence of peaks corresponding to the phenolic carbon and the imine of the salen moiety at $162-165 \mathrm{ppm}$. Additionally, a single ethynyl signal at $90 \mathrm{ppm}$ was observed (Fig. S6†).

\section{Gas adsorption in polymers}

Methods for the activation of POPs were initially probed as a step towards examining their gas sorption properties. The activation of the polymers was achieved by initially immersing the newly synthesised POP materials in DMF $(10 \mathrm{~mL})$ in an oven at $100{ }^{\circ} \mathrm{C}$ for $1 \mathrm{~h}$, prior to filtration and repetition of the process three times. The polymer was subjected to washing via a Soxhlet washing process with methanol at $80{ }^{\circ} \mathrm{C}$ for $48 \mathrm{~h}$.

The porosities of the POPs were analysed using $\mathrm{N}_{2}$ gas sorption experiments at $77 \mathrm{~K}$ to determine their BET surface areas. All POPs demonstrated Type I BET isotherm behaviour, which is indicative of a microporous material (Fig. 3A). ${ }^{47}$ There is a significant amount of hysteresis, which is commonly observed within highly flexible porous materials. The amorphous nature of the POPs is reflected in the pore size distribution, where there is a wide variety of sizes, consistent with the uncontrolled propagation of the POP (Table 1, Fig. S7†).

$\mathrm{N}_{2}$ and $\mathrm{CO}_{2}$ gas sorption experiments were performed at 298 $\mathrm{K}$ (Fig. 3B). The comparable $\mathrm{N}_{2}$ isotherms indicate that at $298 \mathrm{~K}$, there is a limited uptake of $\mathrm{N}_{2}$ and a preference for $\mathrm{CO}_{2}$ uptake 

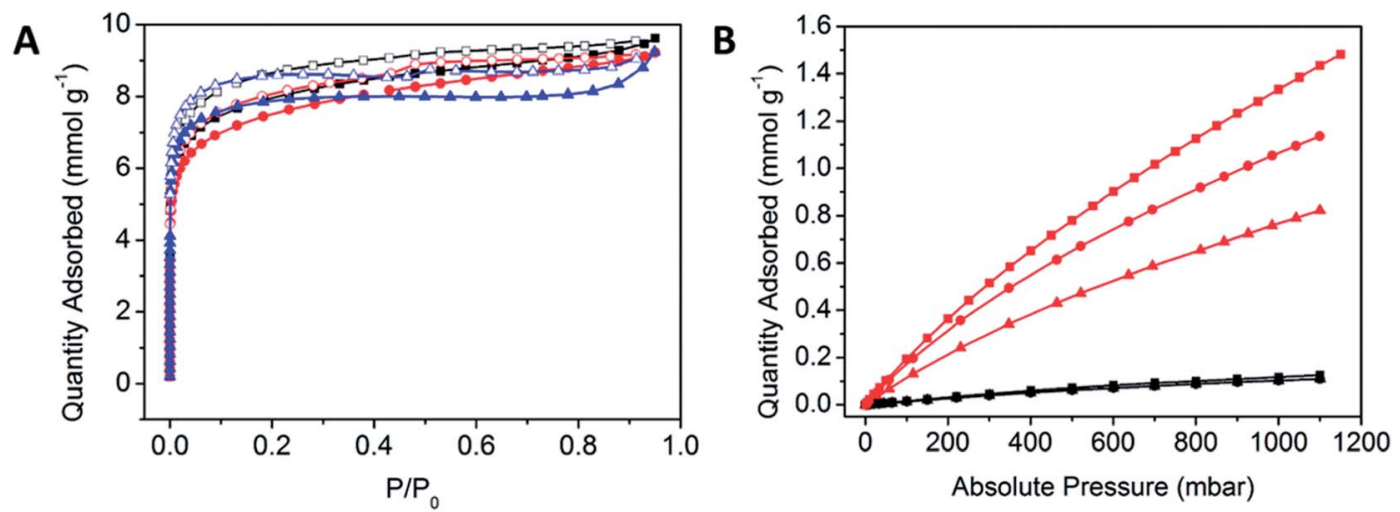

Fig. 3 (A) $\mathrm{N}_{2}$ gas sorption isotherms at $77 \mathrm{~K}$ of POPCo1 (black), POPCo2 (red) and POPCo3 (blue). Closed squares represent $\mathrm{N}_{2}$ adsorption isotherms while open squares represent $\mathrm{N}_{2}$ desorption isotherms. (B) $\mathrm{CO}_{2}$ adsorption isotherms (red) and $\mathrm{N}_{2}$ gas adsorption isotherms (black) at $298 \mathrm{~K}$ of POPCo1 (circles), POPCo2 (triangles) and POPCo3 (squares)

which could arise from differences in the salen backbone. Having to overcome the increased $\pi$-stacking from the aromatic POPCo2 may hinder the adsorption of $\mathrm{CO}_{2}$, while an increased bulk from the bridging diamine may disrupt these interactions, justifying why POPCo1 and POPCo2 have higher uptakes. The isosteric heats of adsorption indicate that there are physisorptive interactions between $\mathrm{CO}_{2}$ and the POP (Table 1, Fig. S8 $\dagger$ ). The slight variations in $-Q_{\text {st }}$ suggest that the backbone of the salen does not play a significant role in the physisorptive interactions between $\mathrm{CO}_{2}$ and the POP. Finally, the $\mathrm{CO}_{2} / \mathrm{N}_{2}$ selectivities $(S)$ were taken with respect to the conditions of a post-combustion flue stream at $298 \mathrm{~K}$, consisting of $\mathrm{N}_{2}\left(P / P_{0}\right.$ $=0.75)$ and $\mathrm{CO}_{2}\left(P / P_{0}=0.15\right)$ (Table 1).

\section{Surface attachment of Co(III) salen POPs to glassy carbon}

POPCo1, POPCo2 and POPCo3 were successfully immobilised onto glassy carbon via electrophoretic deposition by suspending the POP in toluene, with sonication and stirring while a constant DC voltage of $30 \mathrm{~V}$ was applied over a period of $6 \mathrm{~h}$. The reaction was paused every hour to allow for the further sonication of the mixture to disrupt aggregation of the POP. The experiment resulted in coverage of POPCo1, POPCo2 and POPCo3, which could be imaged on the surface via FE-SEM (Fig. 4). POPCo1 and POPCo2 demonstrated better coverage of the glassy carbon plates than POPCo3.

\section{Electrochemistry}

Discrete Co(III) salen complexes. The three discrete $\mathrm{Co}(\mathrm{III})$ complexes were first tested for their redox activity (Table 2,
Fig. S9†). The CV experiment for Co1 revealed one irreversible redox process and two quasi-reversible processes. An additional reduction process could be observed upon inclusion of an aromatic bridging diamine, suggesting that the increased aromaticity of the salen improves its electronic properties. The addition of two methyl groups on the bridging diamine of $\mathbf{C o 3}$ shifted the reduction processes to more cathodic potentials relative to Co2, which was expected from a system containing increased electron density. The solution state $\mathrm{CV}$ of $\mathbf{C o 3}$ was akin to that of Co2.

Co(III) salen POPs. Following the successful surface attachment of the Co(III) salen POPs to glassy carbon, CV experiments were performed to examine their electronic behaviour. For the reduction sweeps, up to four redox processes were observed, corresponding to the reduction of the Co(III) salen. There were fewer reduction processes observed for the aromatic systems. The irreversible $\mathrm{III}_{\mathrm{R}}$ (in POPCo2 and POPCo3) and $\mathrm{IV}_{\mathrm{R}}$ (in POPCo1) reduction process were assigned to the reduction of the imine across the salen metal complex. Incorporation of the salen into the POP appeared to bring the reduction potentials to more cathodic potentials, which is beneficial for any electrochemical applications (Table 3, Fig. S10†).

\section{Spectroelectrochemistry}

Solution state SEC on Co(III) salen complexes. For all discrete complexes, UV-Vis-NIR SEC experiments were performed to elucidate the mechanism for electron transfer (Scheme 2).

Table 1 BET surface areas, free pore volumes, pore size distributions, point selectivities and $-Q_{\text {st }}$ of the synthesised polymers

\begin{tabular}{llllrr}
\hline Polymer & $\begin{array}{l}\text { BET surface area } \\
\left(\mathrm{m}^{2} \mathrm{~g}^{-1}\right)\end{array}$ & $\begin{array}{l}\text { Pore volume } \\
\left(\mathrm{cm}^{3} \mathrm{~g}^{-1}\right)\end{array}$ & Pore size distribution $(\AA)$ & Point selectivity $S^{-Q_{\text {st }}\left(\mathrm{kJ} \mathrm{mol}^{-1}\right)}$ \\
\hline POPCo1 & $657 \pm 1$ & 0.36 & $4.9-7.7,8.3-13$ & 15.4 & $25-27$ \\
POPCo2 & $669 \pm 1$ & 0.37 & $4.8-7.8,8.4-13,17-21$ & 9.5 & $27-29$ \\
POPCo3 & $688 \pm 1$ & 0.36 & $5.6-7.8,8.8-12,14-21$ & 15.1
\end{tabular}


A
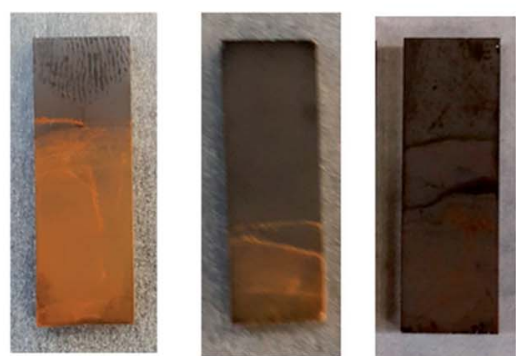

POPCo1 POPCo2 POPCo3

C

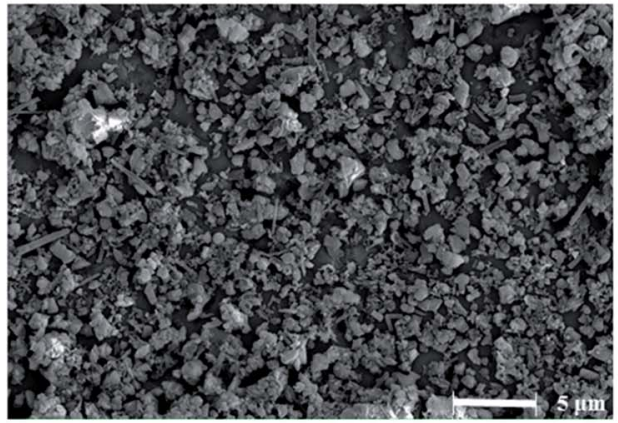

B

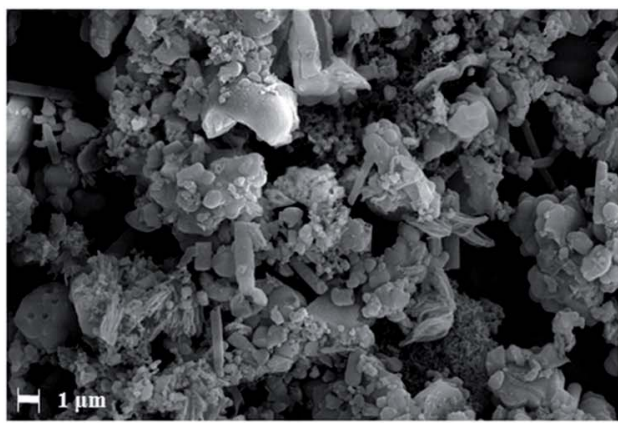

D

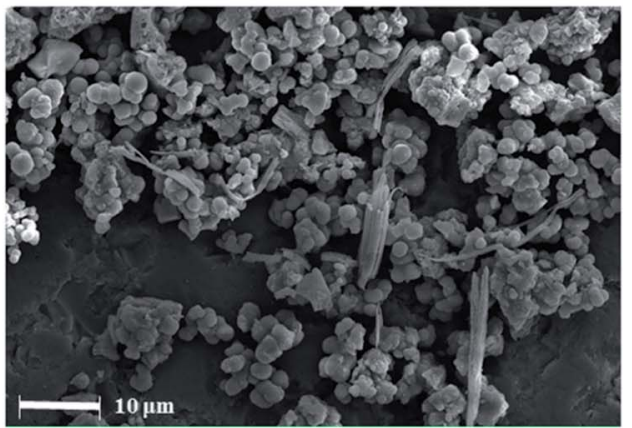

Fig. 4 (A) Coverage of glassy carbon plates by Co(III) polymers. FE-SEM images of (B) POPCo1 (C) POPCo2 and (D) POPCo3.

The first reduction processes in the complexes were consistent with the reduction of the $\mathrm{Co}(\mathrm{III})$ centre to $\mathrm{Co}(\mathrm{I})$. In the SEC for all complexes, an increase in the intensity of the $\mathrm{d}-\mathrm{d}$ bands (16 280 and $19990 \mathrm{~cm}^{-1}$ for Co1, $18570 \mathrm{~cm}^{-1}$ for $\mathbf{C o 2}$ and $15040 \mathrm{~cm}^{-1}$ for Co3) was consistent with a transition from $\mathrm{d}^{6}$ to $\mathrm{d}^{7}$ cobalt species (Fig. S11 $\dagger$ ) and decreases in LMCT bands (24 470 in Co1, 20 980, 25550 and $29600 \mathrm{~cm}^{-1}$ in Co2 and 21720,29550 and $30980 \mathrm{~cm}^{-1}$ for Co3), as seen in other $\mathrm{Co}$ (III) salen complexes. ${ }^{48,49}$ The maintenance of isosbestic points suggests that there is a clean conversion between the $\mathrm{Co}(\mathrm{III})$, $\mathrm{Co}(\mathrm{II})$ and $\mathrm{Co}(\mathrm{I})$ species.

Interesting electronic properties appear after the $\mathrm{II}_{\mathrm{R}}$ reduction. Solution state differential pulse voltammetry (DPV) experiments on Co2 in $0.1 \mathrm{M}\left[\left(n-\mathrm{C}_{4} \mathrm{H}_{9}\right)_{4} \mathrm{~N}\right] \mathrm{PF}_{6} / \mathrm{DMF}$ under $\mathrm{N}_{2}$ reveal a non-Gaussian peak, indicating that the redox couple has a number of underlying processes (Fig. 5A). Despite multiple processes observed, the integration of the area under the combined processes is the same as the integration of the $\mathrm{Fc}^{0} / \mathrm{Fc}^{+}$signal, indicating that only one electron is being transferred. UV-Vis-NIR SEC shows not only evidence for the $\mathrm{Co}(\mathrm{II} / \mathrm{I})$ couple (vide supra), but also an appearance of a radical band at $12690 \mathrm{~cm}^{-1}$. IR SEC experiments were performed on Co2 (4 $\mathrm{mM})$ in $0.1 \mathrm{M}\left[\left(n-\mathrm{C}_{4} \mathrm{H}_{9}\right)_{4} \mathrm{~N}\right] \mathrm{PF}_{6} / \mathrm{MeCN} / \mathrm{DMF}(9: 1)$, which indicated that ligand-based processes are also occurring. The appearance of a new IR stretch at $\nu=1674 \mathrm{~cm}^{-1}$, corresponding to a change in the $\nu_{\mathrm{C}-\mathrm{O}}$ stretch on the phenol, implies that there may be evidence of charge transfer from the $\mathrm{Co}(\mathrm{I})$ metal centre to the ligand (Fig. 5B).

Clear differences in the ligand based reductions are also apparent between the materials. In Co1, the third reduction results in the generation of a number of important bands, consistent with intervalence charge transfer (IVCT). Upon application of a potential at $E_{\mathrm{pc}}=-1.66 \mathrm{~V} v s . \mathrm{Fc}^{0} / \mathrm{Fc}^{+}$, the observation of a weak IVCT band at $10010 \mathrm{~cm}^{-1}$ and a radical band at $12860 \mathrm{~cm}^{-1}$ are suggestive of the formation of the salen radical anion. The lower energies associated with the radical anion band suggest that the $\mathrm{Co}$ (III) metal centre promotes delocalisation. To the best of our knowledge, such IVCT transitions have not been previously reported for $\mathrm{Co}(\mathrm{III})$ salen metal complexes. The appearance of the IVCT band is also accompanied by an increase in the $\pi-\pi^{*}$ transitions at $31080 \mathrm{~cm}^{-1}$, consistent with improved electron delocalisation in the conjugated parts of the salen backbone. In Co2, there is evidence for a weaker IVCT transition. Changes appear in the LMCT and $\mathrm{n}-\pi^{*}$ transitions at 19590 and $23680 \mathrm{~cm}^{-1}$, respectively. This is accompanied by the appearance of a weak IVCT band at $8340 \mathrm{~cm}^{-1}$ and a weak radical band at $12670 \mathrm{~cm}^{-1}$. Similar processes in Co3 are observed. The dominant changes in the UV-Vis spectra are the decrease in the transitions at $20500,25120,29550$ and $30980 \mathrm{~cm}^{-1}$, and the appearance of new transitions at 22490 and $23870 \mathrm{~cm}^{-1}$. This is also supported by the fact that the $\mathrm{III}_{\mathrm{R}}$ process in $\mathrm{Co3}$ is more cathodic than its Co2 analogue, which is consistent with improved delocalisation and electron density increasing the voltage required for reduction of the $\mathbf{C o 3}$ backbone. The absence of an observable IVCT band suggests that the degree of aromaticity affects the nature of the IVCT transition (Fig. 6).

Solid state SEC on Co(III) salen polymers. In situ solid state SEC experiments were performed on POPCo1, POPCo2 and POPCo3. No significant changes were observed on the $I_{R}$ reduction process of the polymer, corresponding to the loss of the chloride anion. Upon the application of a cathodic potential corresponding to the $\mathrm{II}_{\mathrm{R}}$ redox potential in all systems, there was a darkening in the polymers that could be followed with 
Table 2 Redox features for Co(III) salen metal complexes. Ferrocene (1 mM) was used as an internal standard. $\left(0.1 \mathrm{M} \mathrm{C}_{4} \mathrm{H}_{9} N P F_{6} / \mathrm{DMF}\right)$ was the supporting electrolyte. Where available, the peak-peak separation $(\Delta E)$ and the current ratio $\left(i_{\text {pa }} / i_{\text {pc }}\right)$ of reversible and quasi-reversible redox features have been described

\begin{tabular}{|c|c|c|c|c|c|}
\hline Complex & $I_{R}$ & $\mathrm{II}_{\mathrm{R}}$ & $\mathrm{III}_{\mathrm{R}}$ & $\mathrm{IV}_{\mathrm{R}}$ & $\mathrm{Fc}^{0 /+}$ \\
\hline Co1 & $E_{\mathrm{pc}}=-0.49 \mathrm{~V}$ & $\begin{array}{l}E_{1 / 2}=-1.66 \mathrm{~V} \\
\Delta E=64 \mathrm{mV} \\
\left(i_{\mathrm{pa}} / i_{\mathrm{pc}}\right)=0.642\end{array}$ & $\begin{array}{l}E_{1 / 2}=-2.36 \mathrm{~V} \\
\Delta E=60 \mathrm{mV} \\
\left(i_{\mathrm{pa}} / i_{\mathrm{pc}}\right)=0.837\end{array}$ & & $\begin{array}{l}E_{1 / 2}=0 \mathrm{~V} \\
\Delta E=60 \mathrm{mV} \\
\left(i_{\mathrm{pa}} / i_{\mathrm{pc}}\right)=0.914\end{array}$ \\
\hline $\mathrm{Co} 2$ & $E_{\mathrm{pc}}=-0.37 \mathrm{~V}$ & $\begin{array}{l}E_{1 / 2}=-1.56 \mathrm{~V} \\
\Delta E=35 \mathrm{mV} \\
\left(i_{\mathrm{pa}} / i_{\mathrm{pc}}\right)=0.448\end{array}$ & $\begin{array}{l}E_{1 / 2}=-2.23 \mathrm{~V} \\
\Delta E=63 \mathrm{mV} \\
\left(i_{\mathrm{pa}} / i_{\mathrm{pc}}\right)=0.597\end{array}$ & $\begin{array}{l}E_{1 / 2}=-2.43 \mathrm{~V} \\
\Delta E=84 \mathrm{mV} \\
\left(i_{\mathrm{pa}} / i_{\mathrm{pc}}\right)=0.684\end{array}$ & $\begin{array}{l}E_{1 / 2}=0 \mathrm{~V} \\
\Delta E=61 \mathrm{mV} \\
\left(i_{\mathrm{pa}} / i_{\mathrm{pc}}\right)=0.944\end{array}$ \\
\hline
\end{tabular}

Table 3 Redox features for Co(III) salen POPs. Ferrocene (1 mM) was used as an internal standard. $0.1 \mathrm{M}$ LiBF $/ \mathrm{CH}_{3} \mathrm{CN}$ was the supporting electrolyte

\begin{tabular}{lllll}
\hline POP & $\mathrm{I}_{\mathrm{R}}$ & $\mathrm{II}_{\mathrm{R}}$ & $\mathrm{III}_{\mathrm{R}}$ & $\mathrm{IV}_{\mathrm{R}}$ \\
\hline POPCo1 & $E_{\mathrm{pc}}=-0.12 \mathrm{~V}$ & $E_{1 / 2}=-0.80 \mathrm{~V}$ & $E_{\mathrm{pc}}=-1.10 \mathrm{~V}$ & $E_{\mathrm{pc}}=-2.16 \mathrm{~V}$ \\
POPCo2 & $E_{\mathrm{pc}}=-1.42 \mathrm{~V}$ & $E_{\mathrm{pc}}=-2.35 \mathrm{~V}$ & & $E_{1 / 2}=0 \mathrm{~V}$ \\
POPCo3 & $E_{\mathrm{pc}}=-0.86 \mathrm{~V}$ & $E_{\mathrm{pc}}=-1.86 \mathrm{~V}$ & $-2.26 \mathrm{~V}$ & $E_{1 / 2}=0 \mathrm{~V}$ \\
& & &
\end{tabular}

change in the bands at 17410 and $19940 \mathrm{~cm}^{-1}$ (for POPCo1) (Fig. S12 $\dagger$ ) and $18170 \mathrm{~cm}^{-1}$ and $20510 \mathrm{~cm}^{-1}$ (for POPCo3) (Fig. 7). This change is consistent with a $\mathrm{Co}(\mathrm{II} / \mathrm{I})$ process and is reflected by corresponding changes in discrete complexes. There were small changes in the intensity of the peaks for POPCo2. Upon reaching the $\mathrm{III}_{\mathrm{R}}$ potential, losses in intensity occurred in all of the bands in the spectra and the lack of stable isosbestic points indicated a degradation of the polymer. This is also evident from the change in the electrolyte solution from clear and colourless to green.

\section{Electrochemical behaviour in the presence of $\mathrm{CO}_{2}$}

Co(III) salen complexes. Co(III) salen complexes were evaluated for their electrochemical behaviour in the presence of $\mathrm{CO}_{2}$.

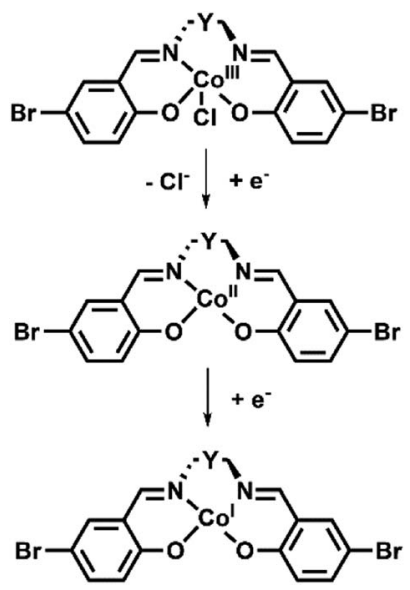

Scheme 2 Proposed mechanism of the Co(III) complexes observed over the initial two reduction processes.
For Co1, there was a slight increase in the magnitude of the current density of $\mathrm{II}_{\mathrm{R}}$ for Co1, indicating that it was not fit for $\mathrm{CO}_{2}$ reduction (Fig. S13A $\dagger$ ). The titration of TFE into the solution did not enhance with the current; therefore, further electrochemical measurements were not pursued. More pronounced changes in the presence of $\mathrm{CO}_{2}$ were observed in Co2, where the $\mathrm{I}_{\mathrm{O}}$ redox process at $E_{\mathrm{pa}}=+0.37 \mathrm{~V}$ vs. $\mathrm{Fc}^{0} / \mathrm{Fc}^{+}$ disappeared, with changes observed in the $\mathrm{I}_{\mathrm{R}}$ redox process at $E_{\mathrm{pc}}=-0.37 \mathrm{~V} v s . \mathrm{Fc}^{0} / \mathrm{Fc}^{+}$(Fig. S13B $\dagger$ ). A slight anodic shift was observed for the $\mathrm{II}_{\mathrm{R}}$ redox process at $E_{1 / 2}=-1.56 \mathrm{~V} v s . \mathrm{Fc}^{0} / \mathrm{Fc}^{+}$, corresponding to the $\mathrm{Co}(\mathrm{II} / \mathrm{I})$ reduction. This may indicate weak association between the reduced species and $\mathrm{CO}_{2}$. The $\mathrm{III}_{\mathrm{R}}$ process at $E_{1 / 2}=-2.23 \mathrm{~V} v s$. $\mathrm{Fc}^{0} / \mathrm{Fc}^{+}$became significant under the $\mathrm{CO}_{2}$ atmosphere and continued to increase with the addition of aliquots of TFE, indicating that a proton source was required to enhance activity. An absence of this increase under $\mathrm{N}_{2}$ with TFE indicates that the process is not only related to the proton reduction of $\mathrm{H}_{2}$, but is likely to arise from the reduction of $\mathrm{CO}_{2}$. The reduction of $\mathrm{CO}_{2}$ by $\mathbf{C o 2}$ follows pseudo-first order kinetics. A plot of $i_{\text {cat }}$ against the square root of $\left[\mathrm{CO}_{2}\right]$ revealed a linear relationship between these two variables, indicating that the process is first order in $\mathrm{CO}_{2}$ (Fig. S14A $\dagger$ ). The plot of $i_{\text {cat }}$ vs. $\left[\mathrm{H}^{+}\right]$showed an initial second order dependence on the proton source, reaching a maximum current density at $0.90 \mathrm{~mA}$ $\mathrm{cm}^{-2}$ after $0.15 \mathrm{M}$ TFE (Fig. S14B $\dagger$ ). Plotting $i_{\text {cat }} v s$. [analyte] revealed a linear relationship (Fig. S14C $\dagger$ ). The concentration of $\mathrm{CO}_{2}$ (0.23 $\mathrm{M}$ in DMF) was well in excess of the concentration of the analyte $(1 \mathrm{mM})$. The titration of TFE into the reaction mixture under an atmosphere of $\mathrm{CO}_{2}$ resulted in the increase in the current density of the $\mathrm{III}_{\mathrm{R}}$ redox process at $E_{\mathrm{pc}}=-2.23 \mathrm{~V} v$. $\mathrm{Fc}^{0} / \mathrm{Fc}^{+}$to a maximum. The addition of TFE into the reaction mixture resulted in a peak ratio $\frac{l_{\text {cat }}}{i_{\mathrm{p}}}$ of 3.34 , corresponding to 

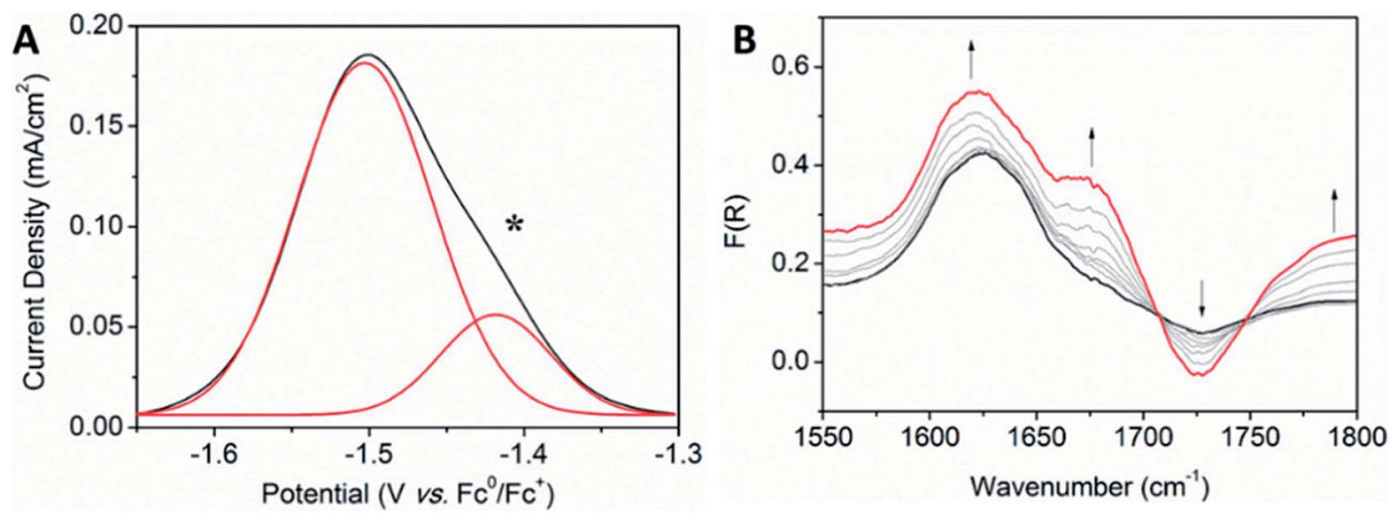

C

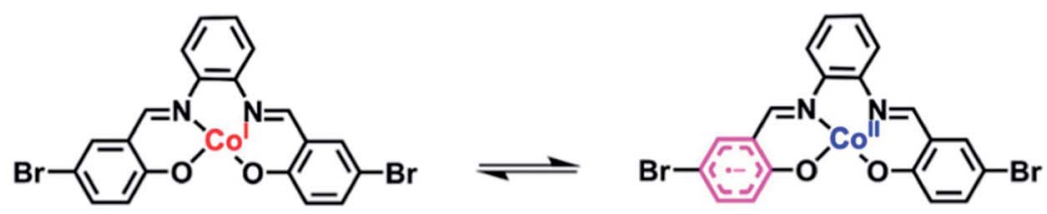

Fig. 5 (A) Solution state DPV of Co2 (1 mM) (scan rate: $0.02 \mathrm{~V} \mathrm{~s}^{-1}, \mathrm{Fc}(1 \mathrm{mM})$ was used as an internal standard) and (B) solution state IR SEC of Co2 $(4 \mathrm{mM})$ upon changing the potential from -0.8 to $-1.5 \mathrm{~V} v$ s. $\mathrm{Ag} / \mathrm{Ag}^{+}$. (0.1 $\mathrm{M}\left[\left(n-\mathrm{C}_{4} \mathrm{H}_{9}\right)_{4} \mathrm{~N}\right] \mathrm{PF} \mathrm{F}_{6} / \mathrm{MeCN} / \mathrm{DMF}(9: 1)$ as the supporting electrolyte). (C) The predicted mechanism of the $I_{R}$ reduction process, showing possible charge transfer between the Co(I) metal and the salen backbone.

a TOF $k[\mathrm{Q}]$ of $2.16 \mathrm{~s}^{-1}$ at $0.63 \mathrm{M}$ TFE. Only a weak association of $\mathrm{CO}_{2}$ with $\mathrm{Co} 2$ was observed (Fig. 8).

Solution state $\mathrm{CV}$ experiments performed on $\mathrm{Co} 3$ in the presence of $\mathrm{CO}_{2}$ resulted in a slight anodic shift in the $\mathrm{II}_{\mathrm{R}}$ redox process at $E_{1 / 2}=-1.57 \mathrm{~V} v s$. $\mathrm{Fc}^{0} / \mathrm{Fc}^{+}$, corresponding to the $\mathrm{Co}(\mathrm{II} / \mathrm{I})$ process and indicating a weak association of $\mathrm{CO}_{2}$ to the metal centre. The $\mathrm{III}_{\mathrm{R}}$ redox process at $E_{1 / 2}=-2.25 \mathrm{~V} v s$. $\mathrm{Fc}^{0} / \mathrm{Fc}^{+}$ increased under $\mathrm{CO}_{2}$ saturation, and was further enhanced to

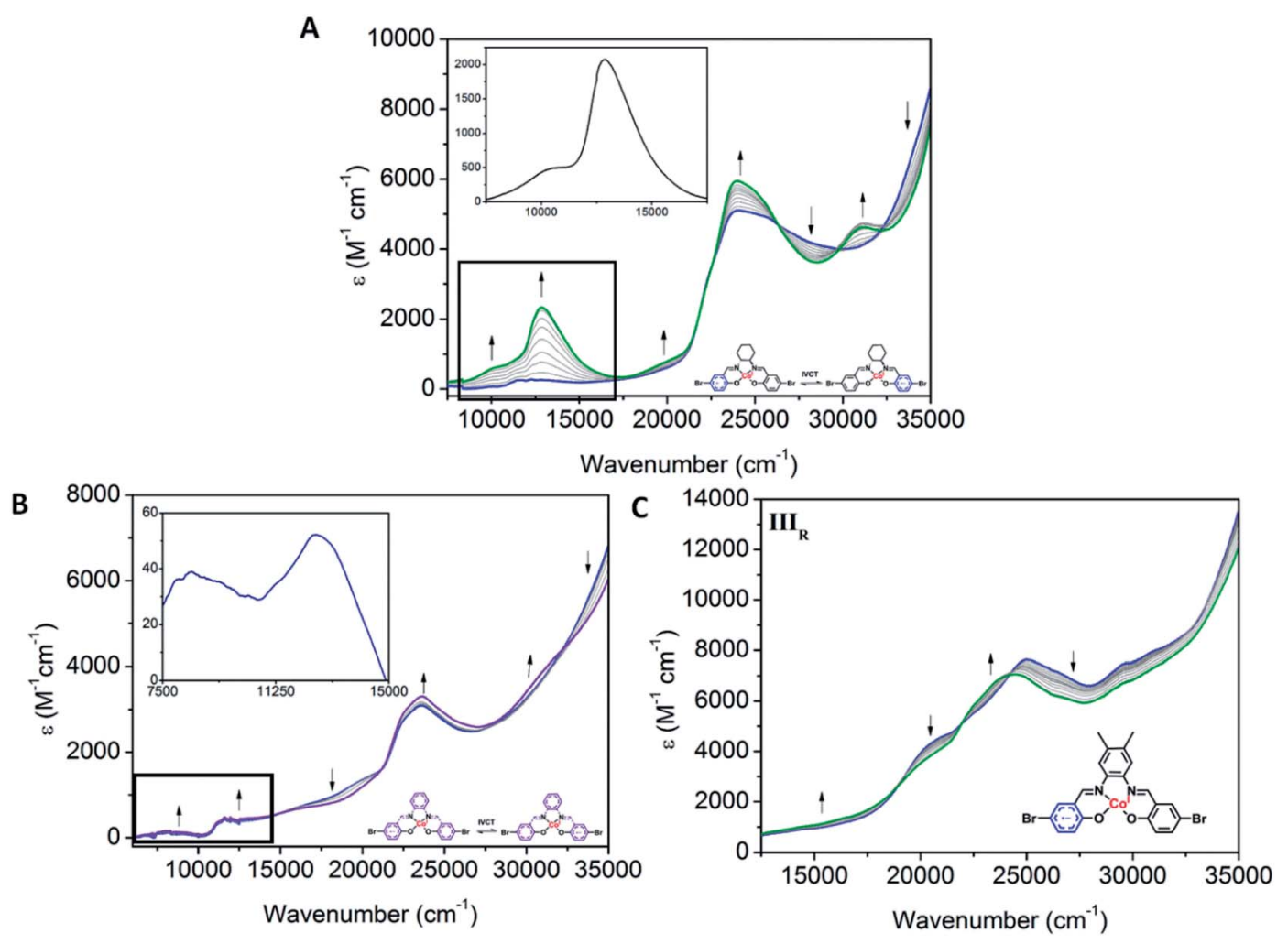

Fig. 6 Solution state UV-Vis-NIR SEC of (A) Co1 (0.61 mM) upon changing the potential from $-1.5 \mathrm{~V}$ to $-1.8 \mathrm{Vvs}$. Ag/Ag ${ }^{+}$, (B) Co2 (0.51 mM) upon changing the potential from -1.6 to $-2.1 \mathrm{~V}$ vs. $\mathrm{Ag} / \mathrm{Ag}^{+}$and $(\mathrm{C}) \mathrm{Co} 3(0.32 \mathrm{mM})$ upon changing the potential from -1.8 to $-2.2 \mathrm{~V} \mathrm{vs}$. $\mathrm{Ag} / \mathrm{Ag}^{+}(0.1 \mathrm{M}$ $\left[\left(n-\mathrm{C}_{4} \mathrm{H}_{9}\right)_{4} \mathrm{~N}\right] \mathrm{PF}_{6} / \mathrm{DMF}$ as the supporting electrolyte). 

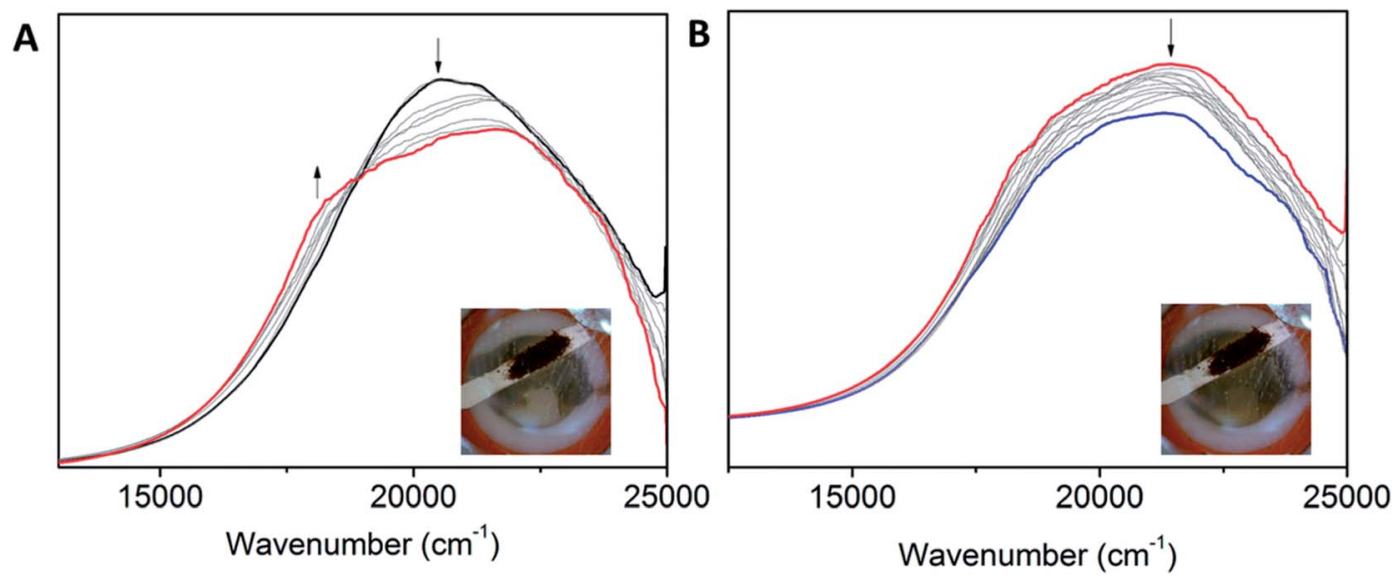

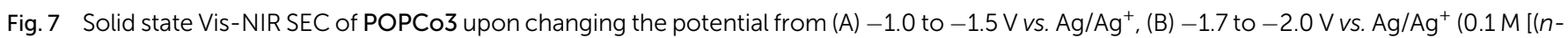
$\left.\mathrm{C}_{4} \mathrm{H}_{9}\right)_{4} \mathrm{NJPF}_{6} / \mathrm{MeCN}$ as the supporting electrolyte).

a maximum upon the addition of successive aliquots of TFE, indicating that a proton source is required to achieve optimal activity. The absence of this enhancement under $\mathrm{N}_{2}$ with the presence of TFE indicates that the process is not solely related to proton reduction, but is more likely to arise from the reduction of $\mathrm{CO}_{2}$. Like $\mathrm{Co} 2, \mathrm{Co} 3$ also follows pseudo first order kinetics. A plot of $i_{\text {cat }}$ against the square root of $\left[\mathrm{CO}_{2}\right]$ showed a linear relationship, suggesting first order kinetics in $\left[\mathrm{CO}_{2}\right]$ (Fig. S15A $\dagger$ ). The plot of $i_{\text {cat }} v s .\left[\mathrm{H}^{+}\right]$shows an initial second order dependence on TFE, prior to reaching saturation (Fig. S15B †). In Co3, saturation of the proton source occurs at lower concentrations than its $\mathbf{C o 2}$ analogue, implying that a lower concentration of a proton source facilitates the reduction of $\mathrm{CO}_{2}$. Plotting $i_{\text {cat }} v s$. [analyte] reveals a linear relationship, indicating a first order dependence of peak current on [analyte] (Fig. S15C †े). $\mathrm{CO}_{2}(0.23 \mathrm{M}$ in DMF) is well in excess of the analyte. Solution state CV experiments were performed on $\operatorname{Co3}(1 \mathrm{mM})$ with varying concentrations of TFE titrated into the solution. The titration of TFE into the reaction mixture under an atmosphere of $\mathrm{CO}_{2}$ resulted in an increase in the current density of the $\mathrm{III}_{\mathrm{R}}$ process to a maximum at $E_{\mathrm{pc}}=-2.25 \mathrm{~V} v s$. $\mathrm{Fc}^{0} / \mathrm{Fc}^{+}$after only two aliquots. Addition of excess TFE after this point resulted in no significant change. The addition of TFE into the reaction mixture yielded a peak ratio $\frac{i_{\text {cat }}}{i_{\mathrm{p}}}$ of 2.98 , corresponding to a TOF $k[\mathrm{Q}]$ of $1.72 \mathrm{~s}^{-1}$ at $0.14 \mathrm{M}$ TFE, which is a smaller turnover than the $\mathbf{C o 2}$ analogue. A negligible association with $\mathrm{CO}_{2}$ was observed.

CPE experiments were performed on solutions of both $\mathbf{C o 2}$ (3.60 mM) with TFE (0.63 M) and Co3 $(1.11 \mathrm{mM})$ with TFE (0.14 $\mathrm{M})$ in $0.1 \mathrm{M}\left[\left(n-\mathrm{C}_{4} \mathrm{H}_{9}\right)_{4} \mathrm{~N}\right] \mathrm{PF}_{6} / \mathrm{DMF} / \mathrm{MeCN}(8: 2)$ under $\mathrm{CO}_{2}$. The generation of $\mathrm{CO}$ was observed in the gas phase from both complexes, as measured from the first 3.73 turnovers over $3 \mathrm{~h}$ in Co2 and measured from the first 4.15 turnovers over the space of $4 \mathrm{~h}$ in $\mathbf{C o 3}$ (Table 4). A linear relationship in the production of gas was maintained throughout the duration of the CPE experiments for both complexes, indicating that the true lifetime of the catalyst may be slightly longer, although there is
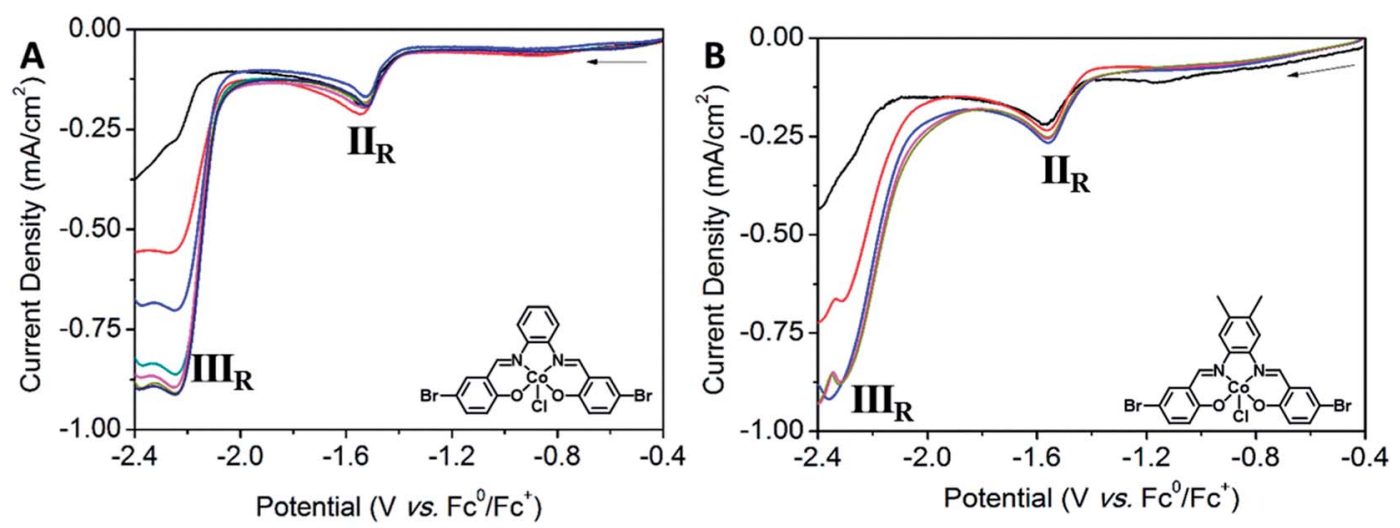

Fig. 8 Solution state $\mathrm{CV}$ showing the electrochemical response of (A) $\mathrm{Co} 2(1 \mathrm{mM})$ under saturation of $\mathrm{N}_{2}(\mathrm{black}), \mathrm{CO}_{2}(\mathrm{red})$ and $\mathrm{CO}_{2}$ with $\mathrm{TFE}(0.7$ mmol-blue, $1.4 \mathrm{mmol}$-green, $2.1 \mathrm{mmol}$-light pink, $2.8 \mathrm{mmol}$-pink, $3.5 \mathrm{mmol}$-brown) and (B) $\mathrm{Co} 3$ (1 mM) under saturation of $\mathrm{N}_{2}$ (black), $\mathrm{CO}_{2}$ (red) and $\mathrm{CO}_{2}$ with TFE $\left(0.7 \mathrm{mmol}-\right.$ blue, $1.4 \mathrm{mmol}$-pink). Return sweeps are not shown for clarity $\left(0.1 \mathrm{M}\left[\left(n-\mathrm{C}_{4} \mathrm{H}_{9}\right)_{4} \mathrm{~N}\right] \mathrm{PF} \mathrm{F}_{6} / \mathrm{DMF}\right.$ as the supporting electrolyte, scan rate: $0.1 \mathrm{~V} \mathrm{~s}^{-1}, \mathrm{Fc}(1 \mathrm{mM})$ was used as an internal standard). 
evidence for both $\mathrm{H}_{2}$ and $\mathrm{CO}$ production plateauing (Fig. S16†). The analyte sustained current densities of $2.57 \mathrm{~mA} \mathrm{~cm}^{-2}$ for $\mathbf{C o 2}$ and $0.4 \mathrm{~mA} \mathrm{~cm}{ }^{-2}$ for $\mathbf{C o 3}$, with CPE experiments revealing a sustained current density over the period of the transformation. This suggests that the electrochemical transformation of $\mathrm{CO}_{2}$ is more likely to be stoichiometric rather than catalytic.

The solution of the electroanalyte was analysed via $^{1} \mathrm{H}$ NMR experiments for solution phase products post electrolysis. After aqueous work up into $\mathrm{D}_{2} \mathrm{O},{ }^{1} \mathrm{H}$ NMR revealed a peak at $\delta=8.00 \mathrm{ppm}$, corresponding to the generation of formic acid (Fig. S17 $\dagger$ ). An NMR time-course experiment was performed concurrently with CPE experiments on Co2, which demonstrated that the peak increased with the CPE. Broadening of the peak may be indicative of paramagnetic metal ions leaching into the solution. In the absence of $\mathrm{CO}_{2}$, the peak corresponding to the formation of formic acid did not appear. No formic acid was observed during experiments where $\mathrm{CO}_{2}$ was present but $\mathbf{C o 2}$ was absent, indicating that the transformation of $\mathrm{CO}_{2}$ into formic acid is due to both the presence of $\mathrm{CO}_{2}$ and $\mathrm{Co2}$.

The prime difference between the analytes of $\mathbf{C o 2}$ and $\mathbf{C o 3}$ lies in the generation of both gaseous phase and solution phase products from the reduction of $\mathrm{CO}_{2}$. Although $\mathrm{CO}$ was formed from both complexes, it was formed in lower efficiencies from the more electron donating Co3. Following the CPE experiments on Co3, the electroanalyte was analysed via ${ }^{1} \mathrm{H}$ NMR experiments after work up into $\mathrm{D}_{2} \mathrm{O}$. No evidence for formic acid was found, which may imply that selectivity for the generation of $\mathrm{CO}$ over formic acid could be achieved by varying the electronics of the salen backbone. Future studies will require the analysis of more electron withdrawing species and their effect on the reduction of $\mathrm{CO}_{2}$.

Co(III) salen POPs. Solid state CV measurements were performed on the polymer series in the presence of $\mathrm{CO}_{2}$. For POPCo1 and POPCo2, there was a loss in intensity of all redox processes, suggesting that $\mathrm{CO}_{2}$ switches off the redox activity of the POP (Fig. S18 $)$ ). Detailed $\mathrm{CO}_{2}$ reduction experiments were therefore not pursued. Significant changes were observed in the solid state CV of POPCo4. Compared to the CV under the $\mathrm{N}_{2}$ atmosphere, a decrease in intensity of the $\mathrm{II}_{R}$ and $\mathrm{III}_{R}$ processes was observed, as well as an anodic shift of the $\mathrm{II}_{R}$ process from $E_{\mathrm{pc}}=-1.86 \mathrm{~V}$ to $-1.73 \mathrm{~V} v s$. $\mathrm{Fc}^{0} / \mathrm{Fc}^{+}$, indicating that $\mathrm{CO}_{2}$ could be irreversibly binding to the species formed from the $\mathrm{II}_{\mathrm{R}}$ process. $T$ he $\mathrm{II}_{\mathrm{R}}$ process increased to a maximum

Table 4 Faradaic efficiencies for the generation of $\mathrm{H}_{2}$ and the conversion of $\mathrm{CO}_{2}$ into $\mathrm{CO}$ and $\mathrm{HCOOH}$. All experiments were performed in $\left(0.1 \mathrm{M}\left[\left(n-\mathrm{C}_{4} \mathrm{H}_{9}\right)_{4} \mathrm{~N}\right] \mathrm{PF}_{6} / \mathrm{DMF} / \mathrm{MeCN}(8: 2)\right.$ with TFE as the supporting electrolyte under $\mathrm{CO}_{2}, E_{\mathrm{pc}}=-1.85 \mathrm{~V} v \mathrm{~s}$. $\mathrm{Ag} / \mathrm{Ag}^{+}$)

\begin{tabular}{llll}
\hline Experiment & $F_{\mathrm{CO}}(\%)$ & $F_{\mathrm{H}_{2}}(\%)$ & $F_{\mathrm{HCOOH}}(\%)$ \\
\hline Solvent & 0 & 0 & 0 \\
Solvent + TFE $(0.7 \mathrm{M})$ & 0 & 12 & 0 \\
Co2 + TFE $(0.63 \mathrm{M})$ & 20 & 13 & 7 \\
Co3 + TFE $(0.14 \mathrm{M})$ & 11 & 14 & 0
\end{tabular}

upon the titration of successive aliquots of TFE. This was accompanied by the generation of a new irreversible process $\mathrm{N}_{1}$ at $E_{\mathrm{pc}}=-1.96 \mathrm{~V} v s . \mathrm{Fc}^{0} / \mathrm{Fc}^{+}$. A CPE experiment was performed in $0.1 \mathrm{M} \mathrm{LiBF}_{4} / \mathrm{MeCN}$ with TFE $(0.5 \mathrm{M})$ at $E_{\mathrm{pc}}=-2.00 \mathrm{~V}$ vs. $\mathrm{Fc}^{0} / \mathrm{Fc}^{+}$under $\mathrm{CO}_{2}$ saturation. Over the space of $3 \mathrm{~h}$, the initial current decreased, before reaching a maximum of 0.67 $\mathrm{mA} \mathrm{cm} \mathrm{cm}^{-2}$ after $1 \mathrm{~h}$. Solution and gas phase analysis were unable to detect products of $\mathrm{CO}_{2}$ reduction, which may be due to the micromolar concentration of $\mathrm{Co}(\mathrm{III})$ metal sites in the polymer in the electrochemical cell and the detection limits of the GC and NMR. This may also suggest degradation of the polymer under electrochemical stimulus.

\section{Conclusions}

This work sought to explore the use of $\mathrm{Co}(\mathrm{III})$ salen metal complexes and POPs as agents for the electrochemical reduction of $\mathrm{CO}_{2}$. A series of discrete $\mathrm{Co}(\mathrm{III})$ bis-bromo terminated salen metal complexes were synthesised and characterised using NMR, UV-Vis-NIR, IR, CV and various SEC techniques to understand their physical and electrochemical properties. The two salen metal complexes, $\mathbf{C o 2}$ and $\mathbf{C o 3}$, successfully reduced $\mathrm{CO}_{2}$ to $\mathrm{CO}$ in $20 \%$ and $11 \%$ Faradaic efficiencies, respectively, suggesting scope to use these complexes as multi-electron reducing agents. Formic acid was also observed as a product of $\mathrm{CO}_{2}$ reduction in $\mathbf{C o 2}$ but not in $\mathbf{C o 3}$, implying that a more electron poor salen metal complex improves the conversion of $\mathrm{CO}_{2}$ into commodity chemicals. Further functionalisation of the bridging diamine may allow for the selectivity of products to be tuned. This work has shown the potential for expanding the studies of $\mathrm{Co}$ (III) salen complexes as reducing agents for twoelectron transfer reactions; however, additional work is required to improve the stability of the electrogenerated imine radical that forms.

The discrete salen complexes were successfully incorporated into POP materials through the Sonogashira-Hagihara reaction with TPA to generate POPCo1, POPCo2 and POPCo3, and were characterised by UV-Vis-NIR, IR, elemental analysis, FE-SEM, solid state NMR and gas sorption. The polymers were found to be porous, with BET surface areas up to $690 \mathrm{~m}^{2} \mathrm{~g}^{-1}$ (comparable with those reported in the literature). ${ }^{21,27,49}$ The successful reduction of $\mathrm{CO}_{2}$ into $\mathrm{CO}$ and formic acid by the discrete complexes led to the examination of the electrochemical properties of the POPs through solid state CV, CPE and SEC experiments. It was possible to use mild EPD conditions to adhere the POP materials to the conductive glassy carbon surface as a thin film, which could be characterised through FE-SEM. Solid state CV experiments revealed a number of irreversible processes for these polymers, suggesting that the instability of the POP material for electrochemical purposes arises from the imine core. When exposed to $\mathrm{CO}_{2}$, the redox behaviour was turned off, suggesting that there is an irreversible chemical transformation of $\mathrm{CO}_{2}$ in the polymer, which could be confirmed from Vis-NIR SEC. There is further scope to address this shortcoming by reinforcing the stability of the imine. 


\section{Conflicts of interest}

The authors declare no conflicts of interest.

\section{Acknowledgements}

This work was supported by the Australian Research Council (ARC) and the Science and Industry Endowment Fund (SIEF) as part of the 'Solving the Energy Waste Roadblock' venture. We gratefully acknowledge Dr Danielle Kennedy at the Commonwealth Scientific and Industrial Research Organisation (CSIRO) for her support in the provision of an OCE PhD top-up scholarship for M. B. S. We are also grateful to Dr Charles Machan from The University of Virginia and Dr Mark Reineke from The University of California, San Diego for their assistance with IR SEC and bulk electrolysis measurements, Dr Carol Hua for guidance on UV-Vis-NIR SEC and Dr Dorothy Yu for the analysis of the polymer samples via ICP-OES. S.M.C was supported by a grant from the office of Basic Energy Sciences, Department of Energy, under Award DE-FG02-08ER46519. C. P. K. gratefully acknowledges NSF (CHE-1145893) for support.

\section{References}

1 R. Carapellucci, L. Giordano and M. Vaccarelli, Analysis of $\mathrm{CO}_{2}$ Post-combustion Capture in Coal-fired Power Plants Integrated with Renewable Energies, J. Photosci., 2015, 82, 350-357, DOI: 10.1016/j.egypro.2015.11.801.

2 R. Barker, Y. Hua and A. Neville, Internal corrosion of carbon steel pipelines for dense-phase $\mathrm{CO}_{2}$ transport in carbon capture and storage (CCS) - a review, Int. Mater. Rev., 2016, 62(1), 1-31, DOI: 10.1080/09506608.2016.1176306.

3 D. M. D'Alessandro, B. Smit and J. R. Long, Carbon Dioxide Capture: Prospects for New Materials, Angew. Chem., Int. Ed., 2010, 49(35), 6058-6082, DOI: 10.1002/anie.201000431.

4 A. Das and D. M. D'Alessandro, Tuning the functional sites in metal-organic frameworks to modulate $\mathrm{CO}_{2}$ heats of adsorption, CrystEngComm, 2015, 17(4), 706-718, DOI: 10.1039/C4CE01341G.

5 J.-R. Li, R. J. Kuppler and H.-C. Zhou, Selective gas adsorption and separation in metal-organic frameworks, Chem. Soc. Rev., 2009, 38(5), 1477-1504, DOI: 10.1039/ B802426J.

6 J.-R. Li, Y. Ma, M. C. McCarthy, J. Sculley, J. Yu, H.-K. Jeong, P. B. Balbuena and H.-C. Zhou, Carbon dioxide capturerelated gas adsorption and separation in metal-organic frameworks, Coord. Chem. Rev., 2011, 255(15-16), 17911823, DOI: 10.1016/j.ccr.2011.02.012.

7 J. Liu, P. K. Thallapally, B. P. McGrail, D. R. Brown and J. Liu, Progress in adsorption-based $\mathrm{CO}_{2}$ capture by metal-organic frameworks, Chem. Soc. Rev., 2012, 41(6), 2308-2322, DOI: 10.1039/C1CS15221A.

8 E. S. Rubin, J. E. Davison and H. J. Herzog, The cost of $\mathrm{CO}_{2}$ capture and storage, Int. J. Greenhouse Gas Control, 2015, 40, 378-400, DOI: 10.1016/j.ijggc.2015.05.018.

9 D. M. Thomas, J. Mechery and S. V. Paulose, Carbon dioxide capture strategies from flue gas using microalgae: a review,
Environ. Sci. Pollut. Res., 2016, 23(17), 1-15, DOI: 10.1007/ s11356-016-7158-3.

10 R. Wennersten, Q. Sun and H. Li, The future potential for Carbon Capture and Storage in climate change mitigation - an overview from perspectives of technology, economy and risk, J. Cleaner Prod., 2015, 103, 724-736, DOI: 10.1016/j.jclepro.2014.09.023.

11 R. Stanger and T. Wall, Sulphur impacts during pulverised coal combustion in oxy-fuel technology for carbon capture and storage, Prog. Energy Combust. Sci., 2011, 37(1), 69-88, DOI: 10.1016/j.pecs.2010.04.001.

12 J. Wang, Analytical Electrochemistry, John Wiley \& Sons, New Jersey, 2006, p. 250.

13 E. E. Benson, C. P. Kubiak, A. J. Sathrum and J. M. Smieja, Electrocatalytic and homogeneous approaches to conversion of $\mathrm{CO}_{2}$ to liquid fuels, Chem. Soc. Rev., 2009, 38(1), 89-99, DOI: 10.1039/B804323J.

14 C. Amatore and J. M. Saveant, Mechanism and kinetic characteristics of the electrochemical reduction of carbon dioxide in media of low proton availability, J. Am. Chem. Soc., 1981, 103(17), 5021-5023, DOI: 10.1021/ja00407a008.

15 V. A. Davankov and M. P. Tsyurupa, Structure and properties of hypercrosslinked polystyrene-the first representative of a new class of polymer networks, React. Polym., 1990, 13(1), 27-42, DOI: 10.1016/0923-1137(90)90038-6.

16 O. K. Farha, A. M. Spokoyny, B. G. Hauser, Y.-S. Bae, S. E. Brown, R. Q. Snurr, C. A. Mirkin and J. T. Hupp, Synthesis, Properties, and Gas Separation Studies of a Robust Diimide-Based Microporous Organic Polymer, Chem. Mater., 2009, 21(14), 3033-3035, DOI: 10.1021/ cm901280w.

17 H. A. Patel, S. Hyun Je, J. Park, D. P. Chen, Y. Jung, C. T. Yavuz and A. Coskun, Unprecedented hightemperature $\mathrm{CO}_{2}$ selectivity in $\mathrm{N}_{2}$-phobic nanoporous covalent organic polymers, Nat. Commun., 2013, 4, 13571366, DOI: 10.1038/ncomms2359.

18 W. Lu, D. Yuan, D. Zhao, C. I. Schilling, O. Plietzsch, T. Muller, S. Bräse, J. Guenther, J. Blümel, R. Krishna, Z. Li and H.-C. Zhou, Porous Polymer Networks: Synthesis, Porosity, and Applications in Gas Storage/Separation, Chem. Mater., 2010, 22(21), 5964-5972, DOI: 10.1021/ cm1021068.

19 Y. Zhang and S. N. Riduan, Functional porous organic polymers for heterogeneous catalysis, Chem. Soc. Rev., 2012, 41(6), 2083-2094, DOI: 10.1039/C1CS15227K.

20 J. Chun, S. Kang, N. Kang, S. M. Lee, H. J. Kim and S. U. Son, Microporous organic networks bearing metal-salen species for mild $\mathrm{CO}_{2}$ fixation to cyclic carbonates, J. Mater. Chem. A, 2013, 1(18), 5517-5523, DOI: 10.1039/C3TA10477J.

21 H. Li, B. Xu, X. Liu, Sigen A, C. He, H. Xia and Y. Mu, A metallosalen-based microporous organic polymer as a heterogeneous carbon-carbon coupling catalyst, J. Mater. Chem. A, 2013, 1(45), 14108-14114, DOI: 10.1039/ C3TA13128A.

22 P. Pfeiffer, E. Breith, E. Lübbe and T. Tsumaki, Tricyclische orthokondensierte Nebenvalenzringe, Liebigs Ann. Chem., 1933, 503(1), 84-130, DOI: 10.1002/jlac.19335030106. 
23 D. J. Darensbourg. Salen Metal Complexes as Catalysts for the Synthesis of Polycarbonates from Cyclic Ethers and Carbon Dioxide, in Synthetic Biodegradable Polymers, ed. B. Rieger, A. Künkel, W. G. Coates, R. Reichardt, E. Dinjus and A. T. Zevaco, Springer Berlin Heidelberg, Berlin, Heidelberg, 2012; pp. 1-27.

24 H. Khoshro, H. R. Zare, A. Gorji, M. Namazian, A. A. Jafari and R. Vafazadeh, The effect of electronic structure on electrocatalytic behaviors of cobalt Schiff base complexes: Electrosynthesis of 2-phenylacetic acid using carbon dioxide, J. Electroanal. Chem., 2014, 732, 117-121, DOI: 10.1016/j.jelechem.2014.07.039.

25 T. Kurahashi and H. Fujii, One-Electron Oxidation of Electronically Diverse Manganese(III) and Nickel(II) Salen Complexes: Transition from Localized to Delocalized Mixed-Valence Ligand Radicals, J. Am. Chem. Soc., 2011, 133(21), 8307-8316, DOI: 10.1021/ja2016813.

26 T. P. Yoon and E. N. Jacobsen, Privileged Chiral Catalysts, Science, 2003, 299(5613), 1691-1693, DOI: 10.1126/ science.1083622.

27 Y. Xie, T.-T. Wang, X.-H. Liu, K. Zou and W.-Q. Deng, Capture and conversion of $\mathrm{CO}_{2}$ at ambient conditions by a conjugated microporous polymer, Nat. Commun., 2013, 4, 2960, DOI: 10.1038/ncomms2960.

28 M. B. Solomon, T. L. Church and D. M. D'Alessandro, Perspectives on metal-organic frameworks with intrinsic electrocatalytic activity, CrystEngComm, 2017, 19(29), 40494065, DOI: 10.1039/c7ce00215g.

29 M. C. So, S. Jin, H.-J. Son, G. P. Wiederrecht, O. K. Farha and J. T. Hupp, Layer-by-Layer Fabrication of Oriented Porous Thin Films Based on Porphyrin-Containing Metal-Organic Frameworks, J. Am. Chem. Soc., 2013, 135(42), 1569815701, DOI: 10.1021/ja4078705.

30 I. Hod, W. Bury, D. M. Karlin, P. Deria, C.-W. Kung, M. J. Katz, M. So, B. Klahr, D. Jin, Y.-W. Chung, T. W. Odom, O. K. Farha and J. T. Hupp, Directed Growth of Electroactive Metal-Organic Framework Thin Films Using Electrophoretic Deposition, Adv. Mater., 2014, 26(36), 6295-6300, DOI: 10.1002/adma.201401940.

31 H. Fei, S. Pullen, A. Wagner, S. Ott and S. M. Cohen, Functionalization of robust $\mathrm{Zr}(\mathrm{Iv})$-based metal-organic framework films via a postsynthetic ligand exchange, Chem. Commun., 2015, 51(1), 66-69, DOI: 10.1039/ C4CC08218D.

32 C. R. Wade, M. Li and M. Dincă, Facile Deposition of Multicolored Electrochromic Metal-Organic Framework Thin Films, Angew. Chem., Int. Ed., 2013, 52(50), 1337713381, DOI: 10.1002/anie.201306162.

33 C.-W. Kung, J. E. Mondloch, T. C. Wang, W. Bury, W. Hoffeditz, B. M. Klahr, R. C. Klet, M. J. Pellin, O. K. Farha and J. T. Hupp, Metal-Organic Framework Thin Films as Platforms for Atomic Layer Deposition of Cobalt Ions To Enable Electrocatalytic Water Oxidation, ACS Appl. Mater. Interfaces, 2015, 7(51), 28223-28230, DOI: 10.1021/acsami.5b06901.

34 L. Ye, J. Liu, Y. Gao, C. Gong, M. Addicoat, T. Heine, C. Woll and L. Sun, Highly oriented MOF thin film-based electrocatalytic device for the reduction of $\mathrm{CO}_{2}$ to $\mathrm{CO}$ exhibiting high faradic efficiency, J. Mater. Chem. A, 2016, 4(40), 15320-15326, DOI: 10.1039/C6TA04801C.

35 R. Wilson, H. Akhavan-Tafti, R. DeSilva and A. P. Schaap, Comparison Between Acridan Ester, Luminol, and Ruthenium Chelate Electrochemiluminescence, Electroanal., 2001, 13(13), 1083-1092, DOI: 10.1002/15214109(200109)13:13<1083::AID-ELAN1083>3.0.CO;2-D.

36 G. Wang and Y. Lin, Novel counter electrodes based on NiPplated glass and $\mathrm{Ti}$ plate substrate for dye-sensitized solar cells, J. Mater. Sci., 2007, 42(13), 5281-5285, DOI: $10.1007 /$ s10853-006-0395-y.

37 H. Zhu, H. Liu, I. Zhitomirsky and S. Zhu, Preparation of metal-organic framework films by electrophoretic deposition method, Mater. Lett., 2015, 142, 19-22, DOI: 10.1016/j.matlet.2014.11.113.

38 I. Hod, M. D. Sampson, P. Deria, C. P. Kubiak, O. K. Farha and J. T. Hupp, Fe-Porphyrin-Based Metal-Organic Framework Films as High-Surface Concentration, Heterogeneous Catalysts for Electrochemical Reduction of $\mathrm{CO}_{2}$, ACS Catal., 2015, 5(11), 6302-6309, DOI: 10.1021/ acscatal.5b01767.

39 Q.-G. Fu, X.-Y. Nan, X. Chen, W.-L. Wang, H.-J. Li, Y.-Y. Li and L.-T. Jia, Electrophoretic deposition of SiC nanowires onto carbon/carbon composites to improve the interface bonding of Ti-Ni-Si joint, Mater. Des., 2015, 80, 137-143, DOI: 10.1016/j.matdes.2015.04.042.

40 H. E. Gottlieb, V. Kotlyar and A. Nudelman, NMR Chemical Shifts of Common Laboratory Solvents as Trace Impurities, J. Org. Chem., 1997, 62(21), 7512-7515, DOI: 10.1021/ jo971176v.

41 I. S. Zavarine and C. P. Kubiak, A versatile variable temperature thin layer reflectance spectroelectrochemical cell, J. Electroanal. Chem., 2001, 495(2), 106-109, DOI: 10.1016/s0022-0728(00)00394-6.

42 P. M. Usov, C. Fabian and D. M. D'Alessandro, Rapid determination of the optical and redox properties of a metal-organic framework via in situ solid state spectroelectrochemistry, Chem. Commun., 2012, 48(33), 3945-3947, DOI: 10.1039/C2CC30568B.

43 M. L. Clark, B. Rudshteyn, A. Ge, S. A. Chabolla, C. W. Machan, B. T. Psciuk, J. Song, G. Canzi, T. Lian, V. S. Batista and C. P. Kubiak, Orientation of CyanoSubstituted Bipyridine Re(I) fac-Tricarbonyl Electrocatalysts Bound to Conducting Au Surfaces, J. Phys. Chem. C, 2016, 120(3), 1657-1665, DOI: 10.1021/acs.jpcc.5b10912.

44 S. Brunauer, P. H. Emmett and E. Teller, Adsorption of Gases in Multimolecular Layers, J. Am. Chem. Soc., 1938, 60(2), 309319, DOI: 10.1021/ja01269a023.

45 S. W. Kim, S. C. Shim, D. Y. Kim and C. Y. Kim, Synthesis and properties of novel triphenylamine polymers containing ethynyl and aromatic moieties, Synth. Met., 2001, 122(2), 363-368, DOI: 10.1016/S0379-6779(00)00398-2.

46 C. Hua, B. Chan, A. Rawal, F. Tuna, D. Collison, J. M. Hook and D. M. D'Alessandro, Redox tunable viologen-based porous organic polymers, J. Mater. Chem. C, 2016, 4(13), 2535-2544, DOI: 10.1039/C6TC00132G. 
47 D. Dollimore, P. Spooner and A. Turner, The bet method of analysis of gas adsorption data and its relevance to the calculation of surface areas, Surf. Technol., 1976, 4(2), 121160, DOI: 10.1016/0376-4583(76)90024-8.

48 A. R. Silva, T. Mourão and J. Rocha, Oxidation of cyclohexane by transition-metal complexes with biomimetic ligands, Catal. Today, 2013, 203, 81-86, DOI: 10.1016/ j.cattod.2012.07.043.
49 M. H. Alkordi, L. J. Weselinski, V. D'Elia, S. Barman, A. Cadiau, M. N. Hedhili, A. J. Cairns, R. G. AbdulHalim, J.-M. Basset and M. Eddaoudi, $\mathrm{CO}_{2}$ conversion: the potential of porous-organic polymers (POPs) for catalytic $\mathrm{CO}_{2}$-epoxide insertion, J. Mater. Chem. A, 2016, 4(19), 74537460, DOI: 10.1039/C5TA09321J. 